\title{
Radiation fog formation alerts using attenuated backscatter power from automatic lidars and ceilometers
}

\author{
Martial Haeffelin ${ }^{1}$, Quentin Laffineur ${ }^{2}$, Juan-Antonio Bravo-Aranda ${ }^{1}$, Marc-Antoine Drouin ${ }^{3}$, \\ Juan-Andrés Casquero-Vera ${ }^{3,4}$, Jean-Charles Dupont ${ }^{5}$, and Hugo De Backer ${ }^{2}$ \\ ${ }^{1}$ Institut Pierre Simon Laplace, Ecole Polytechnique, Centre National de la Recherche Scientifique, 91128 Palaiseau, France \\ ${ }^{2}$ Royal Meteorological Institute of Belgium, 1180 Uccle, Belgium \\ ${ }^{3}$ Laboratoire de Météorologie Dynamique, Ecole Polytechnique, Centre National de la Recherche Scientifique, \\ 91128 Palaiseau, France \\ ${ }^{4}$ Department of Applied Physic, University of Granada, 18071 Granada, Spain \\ ${ }^{5}$ Institut Pierre Simon Laplace, Université Versailles Saint Quentin-en-Yvelines, 78280 Guyancourt, France
}

Correspondence to: Martial Haeffelin (martial.haeffelin@ipsl.polytechnique.fr)

Received: 25 May 2016 - Published in Atmos. Meas. Tech. Discuss.: 17 June 2016

Revised: 23 September 2016 - Accepted: 10 October 2016 - Published: 7 November 2016

\begin{abstract}
Radiation fog occurs over many locations around the world in stable atmospheric conditions. Air traffic at busy airports can be significantly disrupted because low visibility at the ground makes it unsafe to take off, land and taxi on the ground. Current numerical weather prediction forecasts are able to predict general conditions favorable for fog formation, but not the exact time or location of fog occurrence. A selected set of observations available in near-real time at strategic locations could also be useful to track the evolution of key processes and key parameters that drive fog formation. Such observations could complement the information predicted by numerical weather prediction (NWP) models that is made available to airport forecasters in support of their fog forecast. This paper presents an experimental setup based on collocated automatic lidar and ceilometer measurements, relative humidity measurements and horizontal visibility measurements to study hygroscopic growth of fog condensation nuclei. This process can take several minutes to hours, and can be tracked using lidar- or ceilometer-attenuated backscatter profiles. Based on hygroscopic growth laws we derive a set of parameters that can be used to provide alerts minutes to hours prior to formation of radiation fog. We present an algorithm that uses the temporal evolution of attenuated backscatter measurements to derive pre-fog formation alerts. The performance of the algorithm is tested on 45 independent pre-fog situations at two locations (near Paris, France, and Brussels, Belgium). We find that an alert for pre-fog con-
\end{abstract}

ditions predominantly occurs $10-50$ min prior to fog formation at an altitude ranging 0 to $100 \mathrm{~m}$ above ground. In a few cases, alerts can occur up to $100 \mathrm{~min}$ prior to fog formation. Alert durations are found to be sensitive to the relative humidity conditions found a few hours prior to the fog.

\section{Introduction}

Radiation fog occurs over many locations around the world in stable atmospheric conditions when cooling provides supersaturated conditions, allowing persistent droplet activation and formation of a layer containing liquid water droplets near the ground. When this occurs at busy airports, air traffic can be significantly disrupted because low visibility at the ground makes it unsafe to take off, land and taxi on the ground. So in the case of low visibility at the ground, the rate of take off and landing must be significantly reduced, possibly affecting flying schedules across an entire country or continent. Hence, accurate fog formation and dissipation forecasting could significantly help improve flight planning and reduce fuel usage. Increasing air traffic over the past decade could potentially explain the renewed interest in fog forecasting at airports worldwide, such as in Paris, Belgrade, Melbourne, Kolkata or Cape Town (Van Schalkwyk and Dyson, 2013; Bergot et al., 2015; Boneh et al., 2015; Dutta and Chaudhuri, 2015; Veljović et al., 2015). In some locations, 
fog occurs only a few times per year, yet since it occurs unexpectedly, disruptions and hazards may reach unacceptable levels.

Current numerical weather prediction forecasts are able to predict general conditions favorable for fog formation (e.g., high relative humidity, radiative cooling conditions, moderate mixing), but not the exact time or location of fog occurrence (e.g., Steeneveld et al., 2015; Román-Cascón et al., 2016). Such models lack the vertical and spatial resolution and representation of boundary layer and microphysical processes to accurately represent actual near-surface cooling rates, turbulent mixing, supersaturation and their vertical structure in the surface layer. They typically do not represent the activation processes of fog droplets that depend on the chemical nature of the aerosols, on their size distributions and on typically very low supersaturation conditions accurately. Higher resolution models (i.e., large eddy simulation models) can be used to improve the representation of finescale dynamical and thermodynamical processes; however, microphysical and chemical processes must still be represented using parameterizations. Román-Cascón et al. (2016) provide a detailed overview of recent studies investigating new technical configurations or physical parameterizations to improve fog forecasting skill scores of numerical weather prediction models.

A selected set of observations available in near-real time at strategic locations could also be useful to track the evolution of key processes and key parameters that drive fog formation. Such observations could complement the information predicted by numerical weather prediction (NWP) models by providing true values of key parameters that could make the difference between an imminent formation (or not) of fog and likewise for dissipation. Direct use of satellite- or groundbased observations is already commonly used for short-term precipitation estimates (e.g., Ebert et al., 2007). Statistical methods using measured time series of key parameters are also used for wind or solar power production forecasting.

To illustrate this, let us take the example of radiation fog formation that is characterized by the formation of liquid water in the atmosphere. The phase change from water vapor to liquid water yields a rapid increase in the optical cross sections of scattering particles that are responsible for the rapid decrease in visibility (e.g., Elias et al., 2009). This phase change is preceded by progressive hygroscopic growth of fog condensation nuclei, a process that can take minutes to hours depending on the cooling rate leading to supersaturated conditions (Kokkola et al., 2003). Hygroscopic growth of aerosols has been studied extensively, and physical laws have been established empirically between relative humidity and aerosol optical parameters (e.g., Granados-Muñoz et al., 2015). Such fog formation precursor processes can be tracked with proper instrumentation. The activation process resulting from cooling can occur at the surface or aloft (Haeffelin et al., 2013). Hence it is important to be able to track this process over a sufficiently deep vertical profile to capture activation where it occurs first.

Here we apply hygroscopic growth laws to establish a method that uses attenuated backscatter measured by automatic lidars and ceilometers (ALCs) to track activation of aerosols into fog or low-cloud droplets. As most airports are equipped with ALCs, near-real-time analysis of attenuated backscatter measurements could provide useful warnings to airport forecasters about when radiation fog is likely or not likely to occur. In this paper, we study relationships between aerosol properties, relative humidity and light scattering measured by ALCs (Sect. 3). We present a method and experimental setup to investigate aerosol hygroscopic growth by means of attenuated backscatter profiles and a meteorological station on a tower (Sect. 3). We present a methodology to use attenuated backscatter measurements to derive pre-fog formation alerts (Sect. 4). Finally we discuss the occurrences and characteristics of these alerts based on 45 case studies (Sect. 5).

\section{Sites, instrumental issues and datasets}

\subsection{Sites and instruments used in this study}

This study relies on measurements from two locations, near Paris, France, and Brussels, Belgium. The first site is the SIRTA atmospheric research observatory located in Palaiseau $\left(2.208^{\circ} \mathrm{E}, 48.713^{\circ} \mathrm{N} ; 160 \mathrm{~m}\right.$ a.s.l.), $\sim 20 \mathrm{~km}$ south of Paris city center (Haeffelin et al., 2005). SIRTA is situated on the plateau of Saclay in a suburban environment in the flat Parisian plain, surrounded by small suburban towns, agricultural fields, forests and major roads connecting the suburban areas with the city of Paris. A large suite of state-of-theart active and passive remote sensing instruments and in situ sensors have been operated at SIRTA since 2002. These instruments are used to document atmospheric state variables and relevant meteorological and climatological parameters. SIRTA has hosted major national and international field campaigns, in particular the ParisFog campaign series from 2006 to 2014, during which numerous instruments were gathered each winter (October to March) to monitor dynamical, thermodynamical, radiative, optical and microphysical properties and processes that drive formation, development and dissipation of fog (see Haeffelin et al., 2010; Hammer et al., 2014; Dupont et al., 2016).

Several instruments deployed at SIRTA are of interest to this study, namely a Vaisala CL31 ALC (see main characteristics in Table 1) providing profiles of attenuated backscatter at $910 \mathrm{~nm}$, visibility sensors (Degreane DF20/DF20+) providing visibility at 4 and $20 \mathrm{~m}$ a.g.l. and a tower with in situ sensors providing temperature and relative humidity measurements at 1,2, 5, 10, 20 and $30 \mathrm{~m}$ a.g.1. All measurements are synchronized and processed on the same $1 \mathrm{~min}$ temporal grid. 
Table 1. Main characteristics of the CL31 (SIRTA) and CL51 (Uccle) used in this study.

\begin{tabular}{llrrrrr}
\hline & $\begin{array}{l}\text { Laser } \\
\text { source }\end{array}$ & $\begin{array}{r}\text { Output } \\
\text { laser } \\
\text { energy }\end{array}$ & $\begin{array}{r}\text { Pulse } \\
\text { rate }\end{array}$ & $\begin{array}{r}\text { Altitude } \\
\text { range }\end{array}$ & $\begin{array}{r}\text { Vertical } \\
\text { temporal }) \\
\text { resolution }\end{array}$ & $\begin{array}{r}\text { Full } \\
\text { optical } \\
\text { overlap }\end{array}$ \\
\hline Vaisala & $\begin{array}{l}\text { InGasAs } \\
\text { CL31 }\end{array}$ & $1.2 \mu \mathrm{J}$ & $10 \mathrm{kHz}$ & $0 \mathrm{~m}-7.5 \mathrm{~km}$ & $\begin{array}{r}15 \mathrm{~m} \\
(1 \mathrm{~min})\end{array}$ & $<50 \mathrm{~m}$ \\
Vaisala & InGasAs & $3 \mathrm{~mJ}$ & $6.5 \mathrm{kHz}$ & $0 \mathrm{~m}-15 \mathrm{~km}$ & $\begin{array}{r}10 \mathrm{~m} \\
(1 \mathrm{~min})\end{array}$ & $<500 \mathrm{~m} *$ \\
CL51 & $910 \mathrm{~nm}$ & & & & & \\
\hline
\end{tabular}

* See Wiegner et al. (2014) for details about the CL51 optical overlap function at low altitude.

The second site is the Plateau of Uccle located at Uccle, Belgium $\left(4.350^{\circ} \mathrm{E}, 50.800^{\circ} \mathrm{N}\right.$; $100 \mathrm{~m}$ a.s.l. $), \sim 5 \mathrm{~km}$ south of Brussels city center. It is situated in a residential suburb of Brussels surrounded by woods, grasslands and suburban and urban environments. Three institutions (IRM-KMI, ORBROB and ISAB-BIRA) on the Plateau of Uccle manage the long-term active and passive remote sensing atmospheric instruments and in situ sensors. Three of these instruments are used in this study: a Vaisala CL51 ALC (see main characteristics in Table 1) providing profiles of attenuated backscatter at $905 \mathrm{~nm}$ computed with a resolution of $1 \mathrm{~min}$, a webcam providing horizon images with a sampling rate of $5 \mathrm{~min}$ and in situ sensors providing temperature and relative humidity measurements at $2 \mathrm{~m}$ a.g.l. computed with a resolution of $10 \mathrm{~min}$. This latter dataset was oversampled at $1 \mathrm{~min}$ by repeating the same measurements over each computed interval of $10 \mathrm{~min}$, and is synchronized with the ALC measurements.

\subsection{Automatic lidars and ceilometers}

Automatic single-wavelength backscattering lidars and profiling ceilometers (ALCs) operate at ultraviolet $(355 \mathrm{~nm})$, visible $(532 \mathrm{~nm})$ or near-infrared wavelengths $(880,905$, $1064 \mathrm{~nm}$ ). They provide a vertically resolved signal (with variable vertical resolution on the order of $1-10 \mathrm{~m}$ ) that is proportional to the scattering cross section of molecules (Rayleigh scattering) and particles (Mie scattering) whose sizes range from nanometers to micrometers. ALCs are characterized by robust designs, allowing continuous unattended operation and low-emission power to ensure eye safety. They are also characterized by relatively low signal-to-noise values, in particular during daytime and at high altitude. ALCs are available from several manufacturers.

Several hundred such ALCs are currently operated in Europe (e.g., Haeffelin et al., 2012; DWD ceilometer web page $^{1}$ ). The E-PROFILE program is setting up a framework to centralize and harmonize processing and distribution of EU ALC measurements ${ }^{2}$.

\footnotetext{
${ }^{1}$ http://www.dwd.de/DE/forschung/projekte/ceilomap/ ceilomap_node.html

${ }^{2}$ http://www.eumetnet.eu/e-profile
}

Although these instruments are considered as generalpurpose cloud height sensors, their aerosol profiling capabilities are also recognized (e.g., Markowicz et al., 2008). Absolute calibration of ALC backscatter profiles can be achieved using different techniques (e.g., O'Connor et al., 2004; Wiegner and Geiß, 2012). Then, particle backscatter coefficients can be retrieved with relative errors on the order of $10 \%$ or less (Wiegner and Geiß, 2012). Madonna et al. (2015) point out, however, that ALC calibration can also be affected by variability in external temperature, in water vapor, optical overlap functions, signal-to-noise ratio and dynamic range. Therefore, ALC data must be used with caution when retrieving quantitative aerosol optical properties.

ALCs could be particularly suited for applications where absolute calibration is not needed. For example, tracking the depth of the atmospheric layer over which surface emitted species are mixed (so-called mixing layer) can be done by searching for gradients in the vertical profile of ALC measurements (e.g., Morille et al., 2007; Baars et al., 2008). Determination of gradients does not require prior absolute calibration of the signal. However, understanding how aerosol backscatter profiles can be used to track vertical mixing processes may require more information than just the ALC profile (e.g., Haeffelin et al., 2012; Pal et al., 2013).

A key issue for low-altitude $(0-1000 \mathrm{~m})$ profiling applications is the optical overlap between the emitted laser pulses and the collecting optical field. The optical overlap function ranges between 0 and 1 . It is 0 at the ground and reaches 1 at the altitude where all backscattered photons can be accounted for by the collecting optical field. For mono-axial ALCs, full overlap can be reached at low altitudes (i.e., 20$200 \mathrm{~m}$ ), while for bi-axial ALCs, full overlap can only be reached at higher altitudes (i.e., 500-1500 m). The CL31 and CL51 measurements used in this study have been corrected for incomplete optical overlap by the manufacturer. For our application, CL31 (CL51) data can be exploited starting at $10 \mathrm{~m}(50 \mathrm{~m})$ a.g.1.

\subsection{Radiation fog types used in this study}

Glickman (2000) provides a commonly accepted definition of fog as "water droplets suspended in the atmosphere in the vicinity of the Earth's surface that reduce visibility below 
$1 \mathrm{~km}$ ". In our study, we focus on radiation fog, i.e., fogs that form in conditions characterized by near-surface radiative cooling, decreasing temperature and/or increasing relative humidity near the surface, predominantly under a cloud-free atmosphere. Three distinct types of situations are of interest: (1) vertically developed radiation fog (D-RFOG), (2) shallow radiation fog (S-RFOG) and (3) quasi-radiation fog (QRFOG). Following the definition of Dupont et al. (2016), vertically developed radiation fog exceeds $20 \mathrm{~m}$ in depth. It is most frequently $100-500 \mathrm{~m}$ deep. Shallow radiation fog is less than $20 \mathrm{~m}$ deep. Its depth ranges from 2 to $20 \mathrm{~m}$. The horizontal visibility in the fog layer is less than $1 \mathrm{~km}$ for both types of radiation fog. In quasi-radiation fog, similar to the definition of mist in Glickman (2000), the horizontal visibility ranges between 2 and $3 \mathrm{~km}$ (Dupont et al., 2016), where the low visibility is due to inactivated haze particles (Kokkola et al., 2003). QFOG atmospheric conditions are similar to conditions encountered ahead of shallow or deep RFOG (described above). Our study relies on 45 cases of developed radiation fog, as defined above, observed at SIRTA and Uccle.

\section{Relationships between aerosol, humidity and light scattering}

When relative humidity $(\mathrm{RH})$ increases in the atmosphere, aerosol particles may swell due to water uptake becoming significantly larger than in dry conditions (Seinfeld and Pandis, 1998). This process, called hygroscopic growth, is typically continuous and smooth without sudden increase or reduction of water absorption, except for pure salt particles whose growth is characterized by a sharp increase at the critical humidity (Winkler, 1973). Atmospheric aerosols can be divided into deliquescent species and insoluble species according to their change in mass when humidified where their hygroscopic growth depends on their size and chemical composition (McMurry and Stolzenburg (1989); Svenningsson et al., 1992). Inorganic and sea salts, included in fine and coarse modes, respectively, show a high hygroscopicity, whereas black carbon and organic matter (fine mode) and mineral dust (coarse mode) show a low or very low hygroscopicity (Zieger et al., 2013; Titos et al., 2014a). However, hygroscopicity can change due to coating processes (Semeniuk et al., 2007). For example, Hatch et al. (2008) indicate that a small amount of coating by humic substances on insoluble mineral particles can enhance the water absorption. In a similar way, Zhang et al. (2008) points out that aged soot particles, coated by sulfuric acid, show a larger hygroscopic growth than fresh soot.

\subsection{Relationship between aerosol particle size and RH}

The relationship between aerosol particle size and RH has been studied in depth (e.g., Hänel, 1976; Pitchford and McMurry, 1994; Hämeri et al., 2000). Typically, this relationship is described by the aerosol diameter growth factor, $g(\mathrm{RH})$, defined as the wet-to-dry particle radius ratio $\left(r / r_{\mathrm{d}}\right)$. It is expressed as

$g(\mathrm{RH})=\left(1+\frac{\rho_{\mathrm{d}}}{\rho_{\mathrm{W}}} \mu(\mathrm{RH}) \frac{\mathrm{RH}}{1-\mathrm{RH}}\right)^{\frac{1}{3}}$,

where RH has been expressed as a fraction, $\rho_{\mathrm{d}}$ and $\rho_{\mathrm{w}}$ are the dry particle and water density, respectively, and $\mu(\mathrm{RH})$ is the linear mass increase coefficient (Hänel, 1976).

Atmospheric RH alters the optical and microphysical properties of atmospheric aerosols due to aerosol hygroscopic growth. For example, the mass scattering efficiency of aerosol particles depends on their particle size and refractive index, the latter characterized by the chemical composition (Pilinis and Pandis, 1995). Conversely to the particle size increase, the refractive index (both real and imaginary parts) decreases with increasing $\mathrm{RH}$, changing the lidar backscatter-to-extinction ratio. The real part of the water refractive index is lower than the aerosol one, leading to a decrease in scattering. The imaginary part of water is near zero and thus, a decrease in absorption can be expected. However, the refractive index decrease is not large enough to counteract the increase in particle cross section that is proportional to the radius squared. Thus, the size dependence dominates, leading to an increase in scattering as RH increases.

Due to this phenomenon long-term in situ measurements of aerosol optical and microphysical properties are usually performed at standardized dry conditions (WMO/GAW, 2003). Many investigators (e.g., Kotchenruther and Hobbs, 1998; Kotchenruther et al., 1999; Raut and Chazette, 2007; Randriamiarisoa et al., 2006) have analyzed the relationship between the aerosol light scattering coefficients, $\sigma_{\mathrm{sp}}$, and RH using the semi-empirical equation developed by Kasten (1969), and more rigorously discussed by Hänel (1976):

$\sigma_{\mathrm{sp}}(\mathrm{RH})=\sigma_{\mathrm{sp}}^{\mathrm{dry}}(1-\mathrm{RH})^{-\gamma}$,

where $\sigma_{\mathrm{sp}}^{\mathrm{dry}}$ is the scattering coefficient of dry particles, and $\gamma$ is an empirical fitting parameter. Then, aerosol properties can be computed at any RH using the scattering hygroscopic enhancement factor, $f(\mathrm{RH})$, defined commonly as the ratio of $\sigma_{\mathrm{sp}}$ at a given $\mathrm{RH}, \sigma_{\mathrm{sp}}(\mathrm{RH})$, to that in dry conditions, $\sigma_{\mathrm{sp}}^{\text {dry }}$ :

$f(\mathrm{RH})=\frac{\sigma_{\mathrm{sp}}(\mathrm{RH})}{\sigma_{\mathrm{sp}}^{\mathrm{dry}}}$.

Using Eq. (2), Eq. (3) can be rewritten as

$f(\mathrm{RH})=\left(\frac{1-\mathrm{RH}}{1-\mathrm{RH}_{\mathrm{dry}}}\right)^{-\gamma}$,

for a reference value of $\mathrm{RH}, \mathrm{RH}_{\text {dry }}$, where no hygroscopic growth is expected. This is one of the physical parameters commonly applied to describe aerosol hygroscopicity (Hänel, 1976; Zieger et al., 2013; Titos et al., 2014b 
and references therein). According to Wulfmeyer and Feingold (2000), this function is mainly sensitive to the mass fraction of soluble material of the internally mixed aerosol (also called solubility). It is worth noting that $g(\mathrm{RH})$ and $f(\mathrm{RH})$ (Eqs. (1) and (4), respectively) are different since the particle shape affects the aerosol optical and hygroscopic properties, leading to significant impact on $f(\mathrm{RH})$.

Even though $f(\mathrm{RH})$ has been mainly derived from $\sigma_{\mathrm{sp}}$, it has been applied to other optical and microphysical properties such as the aerosol-particle extinction coefficient and the volume concentration (Veselovskii et al., 2009) and the aerosol-particle backscatter coefficient (Rodrigues et al., 2003) and fine-mode volume concentration (GranadosMuñoz et al., 2015) derived from lidar measurements. In this regard, Granados-Muñoz et al. (2015) assume that the hygroscopic growth function is valid for all aerosol properties, and thus,

$f_{\zeta}(\mathrm{RH})=\frac{\zeta(\mathrm{RH})}{\zeta\left(\mathrm{RH}_{\mathrm{ref}}\right)}$,

where $f_{\zeta}(\mathrm{RH})$ is the hygroscopic factor obtained for an aerosol property, $\zeta(\mathrm{RH})$, and $\mathrm{RH}_{\text {ref }}$ is the reference $\mathrm{RH}$ for which no hygroscopic growth is expected. These studies use the vertical variation of aerosol-particle properties within a well-mixed layer, where $\mathrm{RH}$, measured by radiosondes, increases/decreases with height. The advantage of this technique, as opposed to laboratory studies or most in situ studies, is that it can provide relatively continuous altituderesolved measurements without perturbing the aerosol or its surroundings. Additionally, RH ranges analyzed by in situ measurements usually remain below $90-95 \%$ to prevent condensation on the instrumentation (Titos et al., 2014b). The obvious disadvantages are as follows:

- the limited occasions for which the same aerosol type exists in a given portion of a profile that is characterized by widely changing RH because the sampled aerosols are not controlled;

- the requirements of collocated aerosol-particle properties (e.g., lidar) and RH (e.g., radiosonde) vertical profiles.

In this work, we propose a new experimental setup to track the aerosol-particle hygroscopic growth by means of an ALC and a hygrometer installed in a tower. The theoretical basis and the experimental setup are explained in the next section.

\subsection{Aerosol-particle hygroscopic growth by ceilometer: theoretical basis and experimental setup}

The ALC signal is expressed by

$P(t, r)=C(t) \cdot \frac{O(t, r)}{r^{2}} \cdot \beta(t, r) \cdot T^{2}(t, r)$,

where $t$ is the time, $r$ is the range, $C$ represents the heightindependent properties (e.g., the outgoing laser power, detection efficiency, $\ldots), O(t, r)$ is the overlap function, $\beta(t, r)$ is the aerosol backscatter coefficient and $T(t, r)$ is the transmittance. Wavelength dependence has been omitted for simplicity. Defining the attenuated total backscatter coefficient, $\beta_{\text {att }}$, as $\beta \cdot T^{2}$, and correcting the signal by range, the rangecorrected signal, RCS, can be written as follows:

$\operatorname{RCS}(t, r)=C(t) \cdot O(t, r) \cdot \beta_{\text {att }}(t, r)$.

Since the RCS and RH are continuously measured at the tower height, $r_{\mathrm{t}}$, where the hygrometer is installed, we can track the hygroscopic growth during a certain period by dividing the RCS $\left(t, r_{\mathrm{t}}\right)$ by a reference value $\operatorname{RCS}\left(t_{\mathrm{d}}, r_{\mathrm{t}}\right)$ measured at a time considered as dry:

$\frac{\operatorname{RCS}\left(t, r_{\mathrm{t}}\right)}{\operatorname{RCS}\left(t_{\mathrm{d}}, r_{\mathrm{t}}\right)}=\frac{C(t) \cdot O\left(t, r_{\mathrm{t}}\right) \cdot \beta_{\mathrm{att}}\left(t, r_{\mathrm{t}}\right)}{C\left(t_{\mathrm{d}}\right) \cdot O\left(t_{\mathrm{d}}, r_{\mathrm{t}}\right) \cdot \beta_{\mathrm{att}}\left(t_{\mathrm{d}}, r_{\mathrm{t}}\right)}$.

Since $C(t)$ and $O\left(t, r_{\mathrm{t}}\right)$ variations can be neglected over periods of hours,

$\frac{\operatorname{RCS}\left(t, r_{\mathrm{t}}\right)}{\operatorname{RCS}\left(t_{\mathrm{d}}, r_{\mathrm{t}}\right)} \cong \frac{\beta_{\mathrm{att}}\left(t, r_{\mathrm{t}}\right)}{\beta_{\mathrm{att}}\left(t_{\mathrm{d}}, r_{\mathrm{t}}\right)}$.

Then, defining the $\beta_{\text {att }}$ hygroscopic growth function as

$f_{\beta_{\text {att }}}(\mathrm{RH})=\frac{\beta_{\text {att }}(\mathrm{RH})}{\beta_{\text {att }}\left(\mathrm{RH}_{\mathrm{ref}}\right)}$,

the ratio of Eq. (9) is a direct measurement of $f_{\beta_{\text {att }}}(\mathrm{RH})$. However, since both particles and molecules contribute to $\beta_{\text {att }}$, it is necessary to derive the relationship between $f_{\beta_{\text {att }}}(\mathrm{RH})$ and the particle backscatter coefficient, $f_{\beta_{\mathrm{p}}}(\mathrm{RH})$. For this purpose, we firstly show the relationship between $f_{\beta_{\text {att }}}(\mathrm{RH})$ and the total backscatter coefficient, $f_{\beta}(\mathrm{RH})$, substituting the $\beta_{\text {att }}$ definition in Eq. (10):

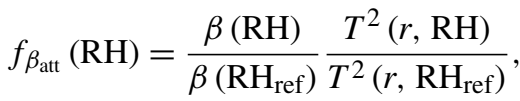

where the transmittance ratio can be rewritten as below:

$f_{\beta_{\text {att }}}(\mathrm{RH})=$

$f_{\beta}(\mathrm{RH}) \exp \left(-2 \int_{0}^{r}\left(\alpha(z, \mathrm{RH})-\alpha\left(z, \mathrm{RH}_{\mathrm{ref}}\right)\right) \mathrm{d} z\right)$,

where $\alpha$ is the extinction coefficient and $z$ is the variable representing altitude. Assuming that the integration range is small enough to assume height-constant extinction, i.e., and using the extinction hygroscopic growth, $f_{\alpha}(\mathrm{RH})$ to rewrite $\alpha(r, \mathrm{RH})$ as $f_{\alpha}(\mathrm{RH}) \alpha\left(r, \mathrm{RH}_{\text {ref }}\right)$, the relationship between $f_{\beta_{\text {att }}}(\mathrm{RH})$ and $f_{\beta}(\mathrm{RH})$ becomes

$f_{\beta_{\text {att }}}(\mathrm{RH})=f_{\beta}(\mathrm{RH}) e^{-2 \cdot r_{\mathrm{mat}} \cdot \alpha\left(R, \mathrm{RH}_{\mathrm{ref}}\right) \cdot\left(f_{\alpha}(\mathrm{RH})-1\right)}$.

In order to quantify the differences between $f_{\beta_{\text {att }}}(\mathrm{RH})$ and $f_{\beta}(\mathrm{RH}), f_{\beta_{\text {att }}}(\mathrm{RH})$ is simulated giving values to $R, f_{\beta}(\mathrm{RH})$, 

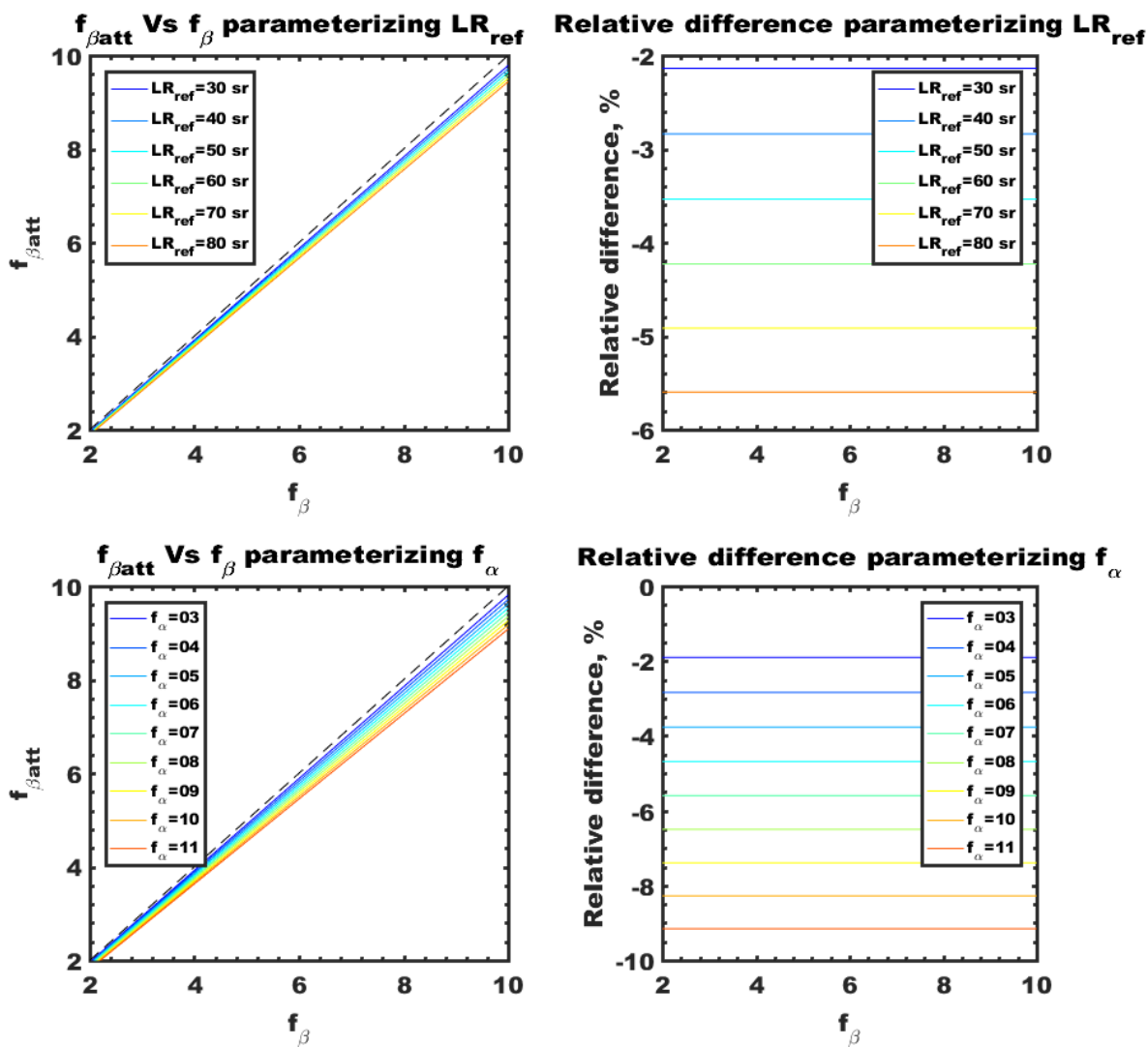

Figure 1. $f_{\beta_{\text {att }}}(\mathrm{RH})$ vs. $f_{\beta}(\mathrm{RH})$ and their relative differences (in \%) parameterizing LR ( $\left.\mathrm{RH}_{\text {ref }}\right)$ (top) and parameterizing $f_{\alpha}(\mathrm{RH})($ bottom). Parameterization values are shown in the labels. $1: 1$ lines are shown as dashed blue lines where relevant.

$f_{\alpha}(\mathrm{RH})$ and $\alpha\left(R, R H_{\text {ref }}\right): r_{\text {mat }}$ is $30 \mathrm{~m}$ (hygrometer altitude), $f_{\beta}(\mathrm{RH})$ and $f_{\alpha}(\mathrm{RH})$ vary in the range $[2,10]$ and $[3,11]$ (assuming that $f_{\beta}(\mathrm{RH})<f_{\alpha}(\mathrm{RH})$ ) and $\alpha\left(r_{\text {mat }}, \mathrm{RH}_{\mathrm{ref}}\right)$ has been parameterized by varying the lidar ratio (LR) at $\mathrm{RH}_{\text {ref }}$ in the range $[30,80]$ sr with $\beta\left(r_{\text {mat }}, \mathrm{RH}_{\text {ref }}\right)=2 \times$ $10^{-6} \mathrm{~m}^{-1} \mathrm{sr}^{-1}$. As it can be seen in Fig. $1, f_{\beta_{\text {att }}}(\mathrm{RH})$ and $f_{\beta}(\mathrm{RH})$ are very similar, with differences less than $10 \%$.

Next we study the relationship between the total, $f_{\beta}(\mathrm{RH})$, and particle, $f_{\beta_{\mathrm{p}}}(\mathrm{RH})$, backscatter coefficient hygroscopic growth. According to their definition, the hygroscopic growth of the total-to-particle backscatter coefficient ratio is expressed by

$\frac{f_{\beta}(\mathrm{RH})}{f_{\beta_{\mathrm{p}}}(\mathrm{RH})}=\frac{\beta(\mathrm{RH}) / \beta\left(\mathrm{RH}_{\mathrm{ref}}\right)}{\beta\left(\mathrm{RH}_{\mathrm{ref}}\right) / \beta_{\mathrm{p}}\left(\mathrm{RH}_{\mathrm{ref}}\right)}$.

Since $\beta=\beta_{\mathrm{m}}+\beta_{\mathrm{p}}$ and the backscattering ratio, $R$, is defined by $R=\frac{\beta}{\beta_{\mathrm{m}}}$, the previous equation can be rewritten in terms of $R$ as follows:

$\frac{f_{\beta}(\mathrm{RH})}{f_{\beta_{\mathrm{p}}}(\mathrm{RH})}=\frac{R(\mathrm{RH})}{R\left(\mathrm{RH}_{\mathrm{ref}}\right)} \frac{\left(R\left(\mathrm{RH}_{\mathrm{ref}}\right)-1\right)}{(R(\mathrm{RH})-1)}$.

Considering that the particle backscattering is much greater than the molecular one for large wavelengths (i.e.,

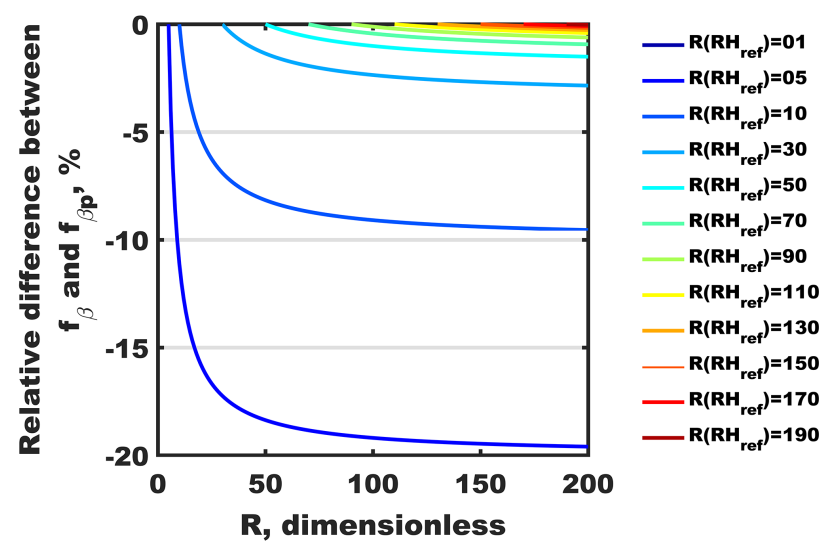

Figure 2. Relative difference between $f_{\beta}(\mathrm{RH})$ and $f_{\beta_{\mathrm{p}}}(\mathrm{RH})$ for different $R\left(\mathrm{RH}_{\mathrm{ref}}\right)$ parameterized according to the label.

$R \gg 1$ ), we can neglect the difference between $f_{\beta}(\mathrm{RH})$ and $f_{\beta_{\mathrm{p}}}(\mathrm{RH})$ since $R(\mathrm{RH}) \approx(R(\mathrm{RH})-1)$. Figure 2 shows the relative differences between $f_{\beta}(\mathrm{RH})$ and $f_{\beta_{\mathrm{p}}}(\mathrm{RH})$ for different backscattering ratios parameterizing $R\left(\mathrm{RH}_{\mathrm{ref}}\right)$. As it can be seen, $R$ values larger than 5 are enough to ensure a relative difference between $f_{\beta}(\mathrm{RH})$ and $f_{\beta_{\mathrm{p}}}(\mathrm{RH})$ below $10 \%$. 


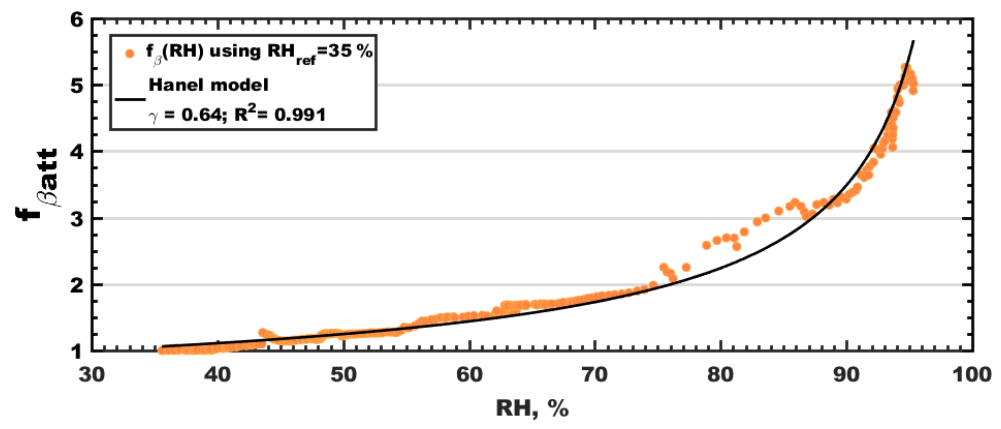

Figure 3. $f_{\beta_{\text {att }}}(\mathrm{RH})$ as function of relative humidity (orange dots) measured at $30 \mathrm{~m}$ a.g.l. on 10 March 2013 at SIRTA and its Hänel function fit (black line).

Therefore, although $f_{\beta_{\text {att }}}(\mathrm{RH})$ is influenced by the particle and molecular contribution, it has been demonstrated that it can provide information about the aerosol-particle hygroscopic growth. Based on this theory, we used synergetic measurements of a CL31 ALC and a hygrometer located at $30 \mathrm{~m}$ in a measurement tower. Distance between the ALC and the tower is about $10 \mathrm{~m}$. Figure 3 shows the $f_{\beta_{\text {att }}}(\mathrm{RH})$ as function of the relative humidity as well as its fitting to the Hänel function (see Eq. 4). A $\gamma$ parameter of 0.64 is derived from fitting the data. The strong correlation between $f_{\beta_{\text {att }}}(\mathrm{RH})$ and the Hänel function $\left(R^{2}=0.99\right)$ demonstrates the influence of the hygroscopic growth on $\beta_{\text {att }}$. Analyses of five other cases measured at SIRTA yield $\gamma$ parameters ranging from 0.24 to 0.64 (all cases have $R^{2}>0.9$ fitting of $f_{\beta_{\text {att }}}(\mathrm{RH})$ ).

\section{Description of the Predictive Alert of Radiation FOG (PARAFOG) algorithm}

As demonstrated in Sect. 3, the use of $\beta_{\text {att }}$ measurements from ALC in Eq. (10) can provide information about the aerosol-particle hygroscopic growth process. Real-time monitoring of this hygroscopic growth function can provide information on the dynamics of pre-fog aerosol activation processes in the atmosphere from the ground and up in the mixing layer. An algorithm analyzing the temporal evolution of ALC-attenuated backscatter measurements in a $400 \mathrm{~m}$ deep layer above the ground is presented here. This algorithm is intended to provide alerts that aerosol backscatter is changing at a fast rate, which is typically observed when saturation conditions are reached and aerosols activate into cloud or fog droplets. This section presents how ALC measurements can be used to provide pre-fog alerts that could be used to support a decision-making process regarding likelihood of radiation fog occurrence at the ground. Because fog formation, development and dissipation are influenced by multiple processes, analyzing ALC measurements should not be thought as a stand-alone unique fog prediction tool. Rather, such realtime analysis should be used to more precisely identify when and where a critical process is occurring that is likely to lead to fog occurrence at the location where the measurement is made.

\subsection{Critical steps of PARAFOG}

Our algorithm development has two main principles in mind: (1) to clearly identify when conditions are favorable and not favorable for pre-fog alerts because fog is a rare event; hence the alert system should be off most of the time; and (2) to use parameters, analyses and tests that are as widely applicable as possible so that they can be applied to different instruments, locations and atmospheric conditions. Following these principles, the PARAFOG algorithm is based on four critical steps:

1. PARAFOG start: determination of whether conditions are favorable for radiation fog formation and determination of reference ALC-attenuated backscatter profile;

2. hygroscopic growth detection: computation of the rate of change of the hygroscopic growth function;

3. alert levels: computation of pre-fog alert levels depending on the rate of change of hygroscopic growth and ALC-attenuated backscatter;

4. end of PARAFOG: determination of whether conditions are no longer favorable for radiation fog.

\subsubsection{Step 1 (start)}

Fog is a relatively rare event. PARAFOG must be activated in conditions that are potentially favorable for fog formation. PARAFOG must remain off otherwise. Two atmospheric parameters are used to activate PARAFOG: relative humidity that drives the hygroscopic growth of aerosol particles, and sky conditions that drive the infrared radiative cooling of the surface layer. Both parameters play a key role in radiation fog formation. Other parameters could also be used to identify conditions that are potentially favorable for fog formation, such as air temperature temporal gradient and horizontal wind speed, as suggested by Menut et al. (2014), although 

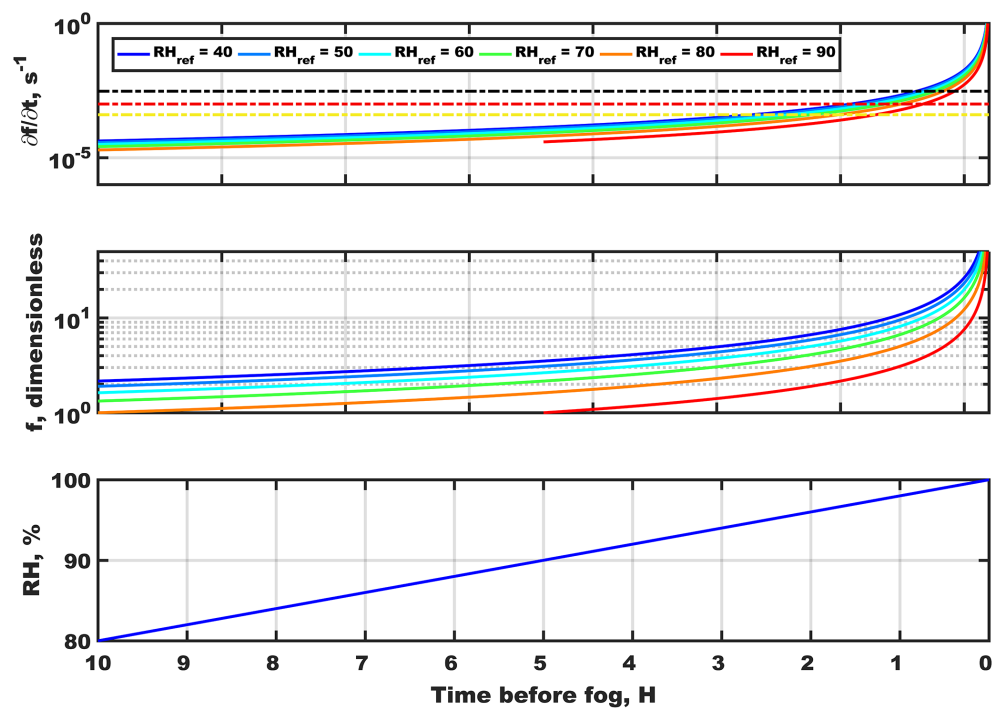

Figure 4. Temporal evolution of $\partial f(\mathrm{RH}) / \partial t$ (top), $f(\mathrm{RH})$ (center) and $\mathrm{RH}$ (bottom) based on Eqs. (4) and (18) for different $\mathrm{RH}_{\text {ref }}$ according to the label and $\gamma=0.7$.

more instrumentation would be required. To turn PARAFOG on, the near-surface relative humidity (typically measured at 2 ma.g.l.) must remain higher than $85 \%$, and cloud cover fraction must remain below $50 \%$ during at least $10 \mathrm{~min}$. Both parameters could be adjusted according to geographical locations. Two cloud cover fractions are considered: (1) cloud cover ranging from 0 to $400 \mathrm{~m}$ a.g.l. and (2) cloud cover ranging from $400 \mathrm{~m}$ to the top of the ALC range. Both cloud cover fractions are derived from the cloud base height measurement of the ALC.

The occurrence of low-level clouds or fog at an altitude less than $400 \mathrm{~m}$ a.g.l. when PARAFOG was already on does not turn off the algorithm. The $400 \mathrm{~m}$ limit is based on a study by Dupont et al. (2016) based on over 100 fog events that show that in conditions favorable for fog formation, the moist surface layer is generally less than $300 \mathrm{~m}$ deep and that clouds that form at altitudes higher than $400 \mathrm{~m}$ very rarely subside all the way to the ground to form fog.

\subsubsection{Step 2 (hygroscopic growth)}

When PARAFOG is turned on, the hygroscopic growth function for each altitude $r_{j}$ (with $j$ the level index) from 0 to $400 \mathrm{~m}$ (a.g.l.) at time $t_{\mathrm{m}}$ is estimated using Eq. (10):

$f_{\beta_{\text {att }}}\left(t_{\mathrm{m}}, r_{j}, \mathrm{RH}\left(t_{\mathrm{m}}, r_{\mathrm{i}}\right)\right)=\frac{\beta_{\text {att }}\left(t_{\mathrm{m}}, r_{j}, \mathrm{RH}\left(t_{\mathrm{m}}, r_{\mathrm{i}}\right)\right)}{\beta_{\text {att }}\left(r_{j}, \mathrm{RH}_{\mathrm{ref}}\left(t_{\mathrm{ref}}, r_{\mathrm{i}}\right)\right)}$,

where $\beta_{\text {att }}\left(r_{j}, \mathrm{RH}_{\text {ref }}\left(t_{\text {ref }}, r_{\mathrm{i}}\right)\right)$ is derived when $\mathrm{RH}\left(r_{\mathrm{i}}\right)$ is minimum at the level $r_{\mathrm{i}}$ ( $i$ is level index where $\mathrm{RH}$ is measured) closest to $r_{j}$ over the time interval $\Delta T$ before PARAFOG was turned on for the first time $\left(t_{\mathrm{on}}\right)$ :

$\mathrm{RH}_{\text {ref }}\left(t_{\text {ref }}, r_{\mathrm{i}}\right)=\mathrm{RH}\left(t_{\mathrm{m}}, r_{\mathrm{i}}\right)$, with $i$ corresponding to

$\left|r_{\mathrm{i}}-r_{j}\right|$,

with $n$ the number of $i$ levels. Identifying $t_{\text {ref }}$ is a critical step because the hygroscopic growth function is very sensitive to the reference $\beta_{\text {att }}$ profile (see discussion in Sect. 5).

A $\Delta T$ of $10 \mathrm{~h}$ is used to reduce the risk to get a $\mathrm{RH}_{\text {ref }}$ higher than $75 \%$ that may reduce the $f_{\beta_{\text {att }}}$ value due to high values of reference $\beta_{\text {att }}$ potentially inducing a delay in fog warning (see Sect. 5). Reference $\beta_{\text {att }}$ profiles that include clouds are rejected.

Figure 4 shows a simulation of the temporal evolution of $f_{\beta_{\text {att }}}\left(t_{\mathrm{m}}, r_{j}, \mathrm{RH}\left(t_{\mathrm{m}}, r_{\mathrm{i}}\right)\right)$ for one level by using Eq. (4) $\left(\mathrm{RH}_{\text {dry }}=\mathrm{RH}_{\text {ref }}\right)$ with $\gamma=0.7$ (Fig. $\left.4 \mathrm{~b}\right)$ and the temporal evolution of $\partial f_{\beta_{\text {att }}} / \partial t$ (Fig. 4a) for a situation where RH changes at a constant rate of $2 \%$ per hour (Fig. 4c), continuously for $10 \mathrm{~h}$. Figure $4 \mathrm{~b}$ shows that the absolute value of $f_{\beta_{\text {att }}}$ is quite sensitive to $\mathrm{RH}_{\text {ref. Hence thresholds to identify }}$ significant hygroscopic growth required to trigger fog alert levels would not be widely applicable. Using the same alert threshold value for $\mathrm{RH}_{\mathrm{ref}}=40$ and $80 \%$ could yield the alert to be delayed by more than $4 \mathrm{~h}$.

To reduce the sensitivity of the alert to initial conditions, we propose to use the temporal gradient of $f_{\beta_{\text {att }}}, \partial f_{\beta_{\text {att }}} / \partial t$ (attenuated backscatter ratio gradient, or RG), as a proxy to monitor the hygroscopic growth dynamics. Figure 4 shows that the curves representing different initial conditions are much closer to each other for $\partial f_{\beta_{\text {att }}} / \partial t$ than for $f_{\beta_{\text {att }}}$. Hence the time at which a threshold is reached is less sensitive to the initial $\mathrm{RH}_{\text {ref }}$ value if $\partial f_{\beta_{\text {att }}} / \partial t$ is used. In PARAFOG, $\partial f_{\beta_{\text {att }}} / \partial t$ is computed as the slope of a $k$-point linear fit fol- 
lowing this equation:

$$
\begin{aligned}
& \mathrm{RG}_{k}\left(t_{\mathrm{m}}, r_{j}\right)= \\
& \frac{\left.\sum_{l=0}^{k-1}\left(t_{\mathrm{m}-l}-\overline{t\left(t_{\mathrm{m}}\right)}\right) \cdot\left(f_{\beta_{\mathrm{at}}\left(t_{\mathrm{m}-l}, r_{j}, \mathrm{RH}\left(t_{\mathrm{m}}, r_{\mathrm{i}}\right)\right.}\right)-\overline{f_{\beta_{\mathrm{att}}}\left(t_{\mathrm{m}}, r_{j}, \mathrm{RH}\left(t_{\mathrm{m}}, r_{\mathrm{i}}\right)\right)}\right)}{\sum_{l=0}^{k}\left(t_{\mathrm{m}-l}-\overline{t\left(t_{\mathrm{m}}\right)}\right)^{2}},
\end{aligned}
$$

where $\overline{t\left(t_{\mathrm{m}}\right)}=\frac{1}{k} \sum_{l=0}^{k-1} t_{\mathrm{m}-l}$ and $\overline{f_{\beta_{\mathrm{att}}}\left(t_{\mathrm{m}}, r_{j}, \mathrm{RH}\left(t_{\mathrm{m}}, r_{\mathrm{i}}\right)\right)}=$ $\frac{1}{k} \sum_{l=0}^{k-1} f_{\beta_{\text {att }}}\left(t_{\mathrm{m}-l}, r_{j}, \operatorname{RH}\left(t_{\mathrm{m}}, r_{\mathrm{i}}\right)\right)$.

The altitude where $\mathrm{RG}_{k}\left(t_{\mathrm{m}}, r_{j}\right)$ is maximum, $H_{\max }\left(t_{\mathrm{m}}\right)$, is used to monitor the level where the hygroscopic growth of aerosol particles is fastest.

\subsubsection{Step 3 (alert levels)}

When PARAFOG is turned on, $\mathrm{RG}_{k}\left(t_{\mathrm{m}}, r_{j}\right)$ is computed at each time step and each altitude. It is then compared to different threshold values to derive pre-fog alerts of different levels. These alerts are intended to provide warning prior to possible formation of radiation fog. The fog alert levels are defined as follows.

- None: even though PARAFOG is on, the ALCattenuated backscatter is not changing significantly compared to the reference conditions.

- Minor: the ALC-attenuated backscatter is changing compared to the reference conditions. The atmospheric conditions support the development of radiation fog. The altitude $H_{\max }\left(t_{\mathrm{m}}\right)$ can change significantly from one time step to the next.

- Moderate: the ALC-attenuated backscatter is changing compared to the reference conditions. The atmospheric conditions support the occurrence of radiation fog. The altitude $H_{\max }\left(t_{\mathrm{m}}\right)$ is found at a height that varies slowly from one time step to the next.

- Severe: the ALC-attenuated backscatter is changing rapidly compared to the reference conditions (1 order of magnitude more rapidly than for a minor-level alert). Formation of droplets and subsequent fog is imminent.

- Fog: fog is detected by the ALC at an altitude ranging from 0 to $400 \mathrm{~m}$ a.g.l.

The thresholds used to define minor-, moderate- and severe-level alerts based on $\mathrm{RG}_{k}\left(t_{\mathrm{m}}, r_{j}\right)$ are shown in Table 2 . They have been derived empirically using 10 cases from the SIRTA dataset. $\mathrm{RG}_{60}\left(t_{\mathrm{m}}, r_{j}\right)$ is derived using Eq. (18) as a slope based on 60 min of measurements, updated at each time step. A period of $60 \mathrm{~min}$ allows significant attenuated backscatter ratio gradients to be detected while eliminating rapid fluctuations. This is consistent with physical time constants observed in radiative cooling condition. Using the threshold shown in Table 2 for minor-level alerts, Fig. 4a reveals that a minor-level alert would appear
Table 2. Thresholds used to define minor-, moderate- and severelevel alerts based on ALC-attenuated backscatter ratio gradients.

\begin{tabular}{lrrr}
\hline & $\mathrm{RG}_{60}\left(\begin{array}{r}\left.t_{\mathrm{m}}, r_{j}\right) \\
\left(\mathrm{s}^{-1}\right)\end{array}\right.$ & $\begin{array}{r}\operatorname{Pr}^{2}\left(t_{\mathrm{m}}, r_{j}\right) \\
\left(\mathrm{m}^{-1} \mathrm{sr}^{-1}\right)\end{array}$ & $\begin{array}{r}\mathrm{RH}\left(t_{\mathrm{m}}, r_{\mathrm{i}}\right) \\
(\%)\end{array}$ \\
\hline Minor & $4 \times 10^{-4}$ & & 90 \\
Moderate & $1 \times 10^{-3}$ & & 95 \\
Severe & $4 \times 10^{-3}$ & & 95 \\
Fog & & $2 \times 10^{-4}$ & \\
\hline
\end{tabular}

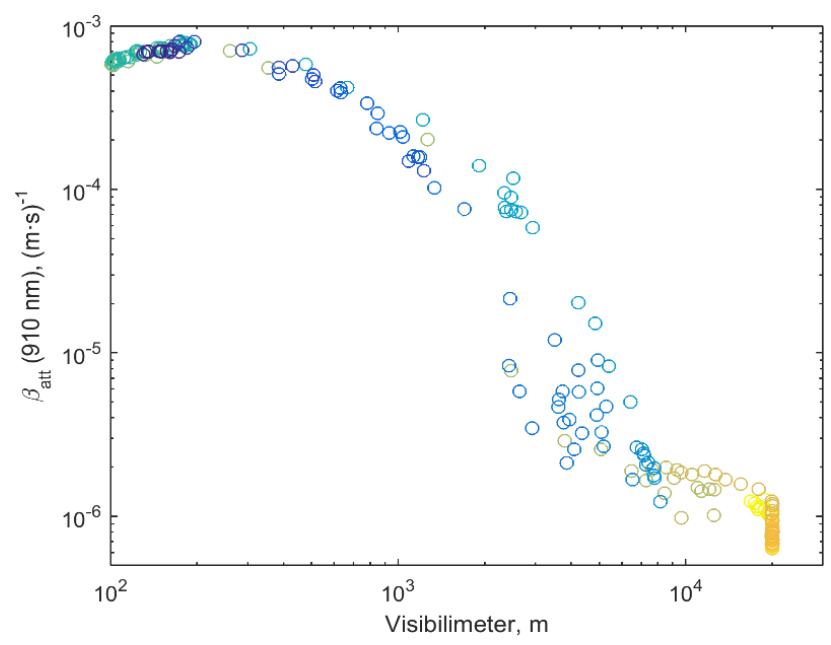

Figure 5. Scatter plot of simultaneous and collocated CL31 $\beta_{\text {att }}(905 \mathrm{~nm})$ and diffusiometer visibility $(550 \mathrm{~nm})$ measured at 20 m a.g.1.

30-60 min earlier for a reference relative humidity of $40 \%$ compared to $80 \%$. A severe-level alert based on a $40 \%$ reference relative humidity is likely to appear about $10 \mathrm{~min}$ earlier than for an $80 \%$ reference condition. Changing the minorlevel alert value by 1 order of magnitude also delays the alert occurrence by $60 \mathrm{~min}$.

The threshold used to define fog-level alert corresponds to an attenuated backscatter value typically observed as the near-surface horizontal visibility drops below $1 \mathrm{~km}$. A time series of simultaneous and collocated CL31-attenuated backscatter and diffusiometer visibility at $20 \mathrm{ma.g.l}$. is shown in Fig. 5. This example (and many others not shown) shows that when the visibility (measured at $550 \mathrm{~nm}$ ) drops below $1 \mathrm{~km}$, the $20 \mathrm{~m}$ attenuated backscatter (measured at $910 \mathrm{~nm}$ ) exceeds $2 \times 10^{-4} \mathrm{~m}^{-1} \mathrm{sr}^{-1}$. To compare, visibilityto-extinction parameterizations (e.g., Nebuloni, 2005) yield an extinction of about $3 \times 10^{-3} \mathrm{~m}^{-1}$ at $905 \mathrm{~nm}$ for a $550 \mathrm{~nm}$ visibility of $1 \mathrm{~km}$ (neglecting absorption by water vapor molecules). Because the extinction is strong in these conditions (scattering by droplets and absorption by water vapor), it is expected that the attenuated backscatter at higher altitudes (in the fog) will decrease quickly with increasing alti- 


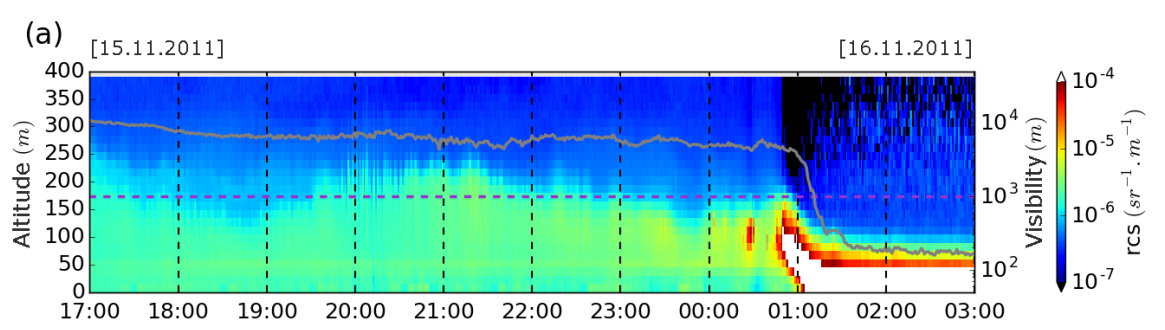

(b)

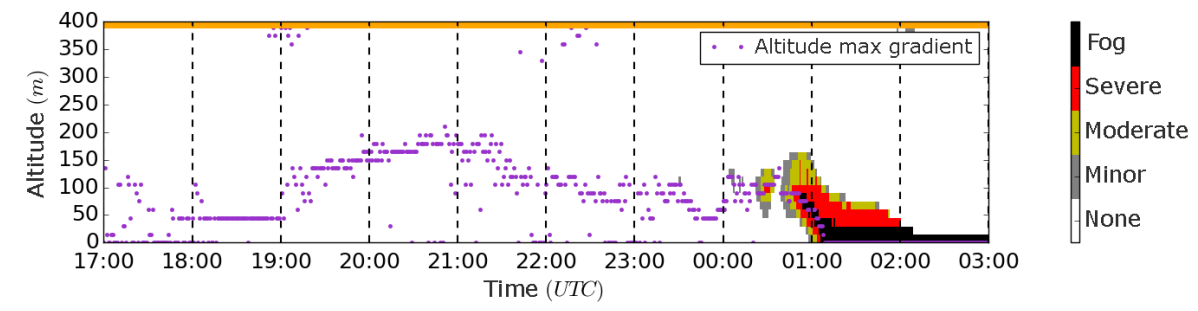

Figure 6. Time series presenting measurements and alert levels in pre-fog conditions on 15-16 November 2011 at SIRTA. (a) ALC-attenuated backscatter (color contours) and horizontal visibility (gray line) measured at $3 \mathrm{~m}$ a.g.l. (b) Alert levels (colors) and altitude of $H_{\text {max }}$ (purple points). The horizontal line at the top of Fig. $6 \mathrm{~b}$ is either green (PARAFOG off) or orange (PARAFOG on). Pre-fog conditions are cloud-free. Aerosol activation occurs at $100 \mathrm{~m}$ a.g.l. Minor-level alert $90 \mathrm{~min}$ before fog formation. Severe alert $30 \mathrm{~min}$ before fog formation.

tude. Hence this threshold will only be valid in the first few ALC measurement gates inside the fog.

\subsubsection{Step 4 (end)}

Several conditions can lead to the termination of a radiation fog alert event. PARAFOG considers the end of the fog if one of the following events occur: (1) occurrence of a cloud cover fraction greater than $50 \%$ in the range $400 \mathrm{~m}$ to top of ALC range; (2) dissipation of cloud or fog layers in the $0-400 \mathrm{~m}$ range; and (3) near-surface relative humidity remaining below $85 \%$ for more than $10 \mathrm{~min}$.

\subsection{Case studies of radiation fog detected by PARAFOG}

We test the performance of the PARAFOG algorithm on two situations prior to deep radiation fog formation at SIRTA and Uccle, as well as one situation prior to a shallow patchy radiation fog at SIRTA, and a quasi-fog at SIRTA. Figure 6 shows the time series of measurements and pre-fog alert levels for the 15-16 November 2011 at SIRTA. Figure 6a shows the calibrated range-corrected attenuated backscatter power provided by the CL31 and the near-surface horizontal visibility. Reference $\beta_{\text {att }}$ are on the order of $1 \times 10^{-6} \mathrm{~m}^{-1} \mathrm{sr}^{-1}$ and $\mathrm{RH}_{\mathrm{ref}}=77 \%$ for this case. Figure $6 \mathrm{~b}$ shows the pre-fog alert levels, $H_{\max }$, and the status of PARAFOG (on/off). Eight hours prior to fog occurrence time, PARAFOG was already on, showing that the near-surface relative humidity exceeded $85 \%$ at 17:00 UTC, while the horizontal visibility exceeded $10 \mathrm{~km} . H_{\max }$ is found at an altitude slowly evolving between 50 and $200 \mathrm{~m}$ a.g.l. between 17:00 and 21:30 UTC. Then, between 21:30 and 00:30 UTC, $H_{\max }$ decreases slowly towards
$100 \mathrm{~m}$ a.g.l. The first alert occurs at 00:20 UTC at $90 \mathrm{~m}$ a.g.l., about $1 \mathrm{~h}$ prior to fog occurrence time. The alert level evolves quickly from minor to moderate to severe in less than $20 \mathrm{~min}$. A fog layer forms at $90 \mathrm{ma.g}$.1. at about 00:50 UTC just $20 \mathrm{~min}$ prior to fog occurrence at the ground. Therefore, this suggests that once fog droplets appear at $90 \mathrm{~m}$ a.g.l., the fog layer starts to subside at a rate of about $300 \mathrm{~m} \mathrm{~h}^{-1}$.

Figure 7 is the same as Fig. 6 for the case of 24 October 2012 at Uccle. Reference $\beta_{\text {att }}$ are on the order of $1 \times 10^{-6} \mathrm{~m}^{-1} \mathrm{sr}^{-1}$ and $\mathrm{RH}_{\mathrm{ref}}=60 \%$ for this case. The PARAFOG algorithm status becomes on $3 \mathrm{~h}$ prior to fog occurrence time. Minor-level alerts appear soon after the algorithm turns on with $H_{\max }$ near $150 \mathrm{~m}$ a.g.l. Consistent prefog alerts near $200 \mathrm{~m}$ a.g.1. occur at 21:45 UTC, $90 \mathrm{~min}$ prior to fog occurrence time. After 22:00 UTC, $H_{\max }$ start to decrease quasi-monotonously at a rate of about $100 \mathrm{~m} \mathrm{~h}^{-1}$.

Figure 8 is the same as Fig. 6 for the case of 19-20 November 2011 at SIRTA. This is a shallow radiation fog situation with patchy fog and highly variable horizontal visibility fluctuating between $20 \mathrm{~m}$ and $2 \mathrm{~km}$ during $10 \mathrm{~h}$. The PARAFOG algorithm status is on during the entire period. Minor- and moderate-level alerts occur at $10 \mathrm{ma}$ a.g.l. from 21:00 to 00:45 UTC. Moderate- and severe-level alerts occur at $10 \mathrm{ma}$ a.l. from 00:45 to 06:00 UTC. $H_{\max }$ values range predominantly $0-50 \mathrm{~m}$ a.g.l., but values exceeding $300 \mathrm{~m}$ a.g.l. are also found nearly every hour.

Figure 9 is the same as Fig. 6 for the case of 9-10 December 2011 at SIRTA. High near-surface relative humidity, clear skies and radiative cooling characterize this situation, but fog formation does not occur. The PARAFOG algorithm status changes between on and off several times during the $10 \mathrm{~h}$ period. $H_{\max }$ values are found anywhere between 0 and 


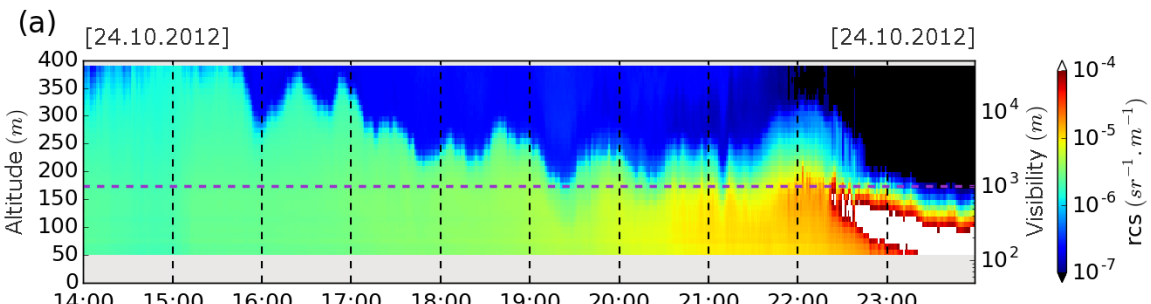

(b)

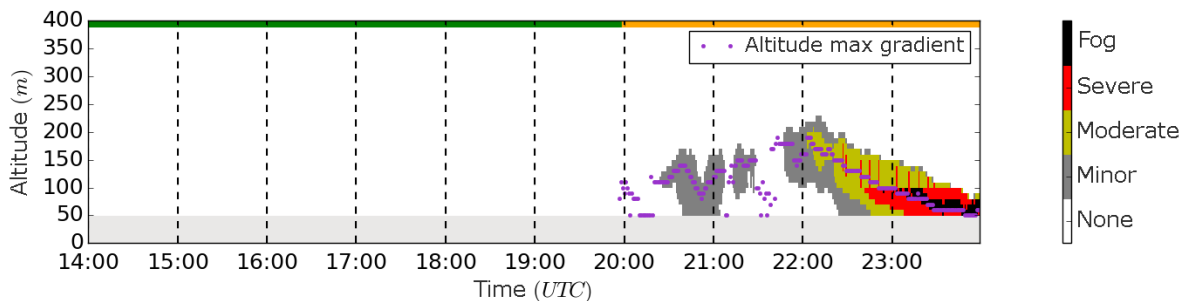

Figure 7. Time series presenting measurements and alert levels in pre-fog conditions on 24 October 2012 at Uccle. (a) ALC-attenuated backscatter (color contours); horizontal visibility not available at Uccle. (b) Alert levels (colors) and altitude of $H_{\text {max }}$ (purple points). The horizontal line at the top of Fig. 7b is either green (PARAFOG off) or orange (PARAFOG on). Pre-fog conditions are cloud-free. Aerosol activation occurs at $100 \mathrm{~m}$ a.g.l. Minor-level alert $180 \mathrm{~min}$ before fog formation at the ground. Severe alert $45 \mathrm{~min}$ before fog formation.

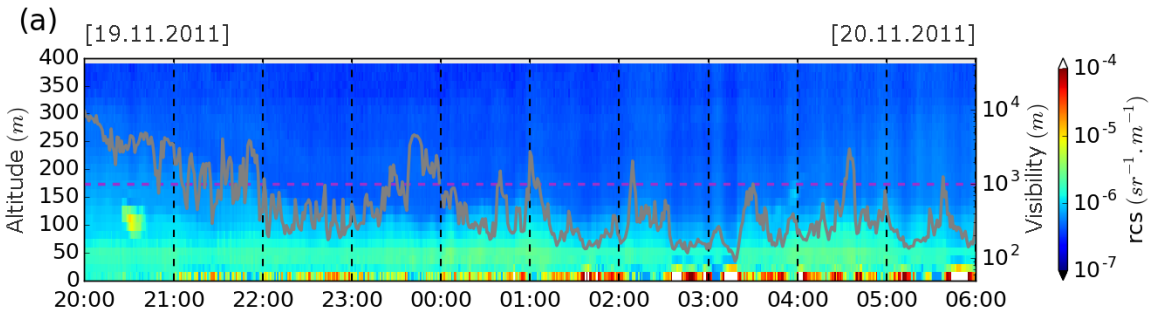

(b)

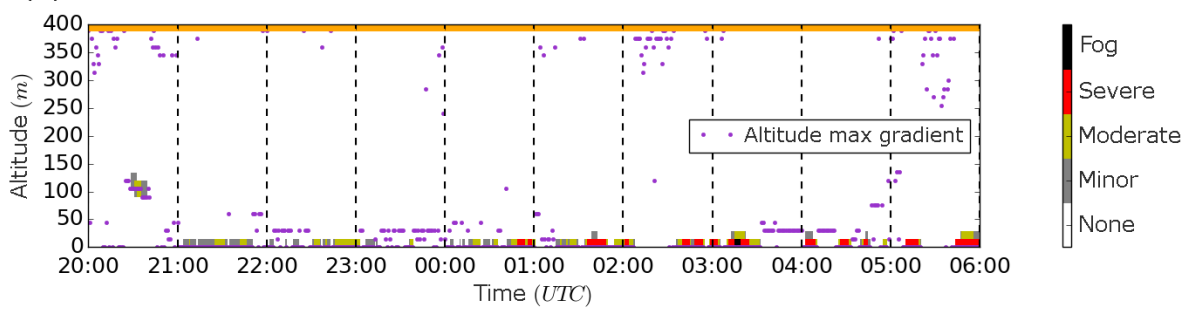

Figure 8. Time series presenting measurements and alert levels in pre-fog conditions on 19-20 November 2011 at SIRTA. (a) ALC-attenuated backscatter (color contours) and horizontal visibility (gray line) measured at $3 \mathrm{~m}$ a.g.l. (b) Alert levels (colors) and altitude of $H_{\mathrm{max}}$ (purple points). The horizontal line at the top of Fig. $6 \mathrm{~b}$ is either green (PARAFOG off) or orange (PARAFOG on). Pre-fog conditions are cloud-free. Aerosol activation occurs at $0 \mathrm{~m}$ a.g.l. Minor-level alert $60 \mathrm{~min}$ before fog formation. Severe alert does not occur before fog formation.

$400 \mathrm{~m}$ a.g.l., showing that there is not a preferred altitude at which aerosol activation is occurring. No pre-fog alerts occur during the $10 \mathrm{~h}$ period. The behavior of the PARAFOG algorithm prior to quasi-fog situations should be tested further to estimate the potential for minor, moderate and severe alerts to occur in such conditions.

\section{Performance of PARAFOG in providing pre-fog alerts}

This section presents the performance of the PARAFOG algorithm in terms of alert occurrences, durations and altitudes. Results are provided for the minor-, moderate-, severe- and fog-level alerts based on about 45 fog cases (fog occurs in each case) observed near Paris and Brussels, and are presented in Table 3. 


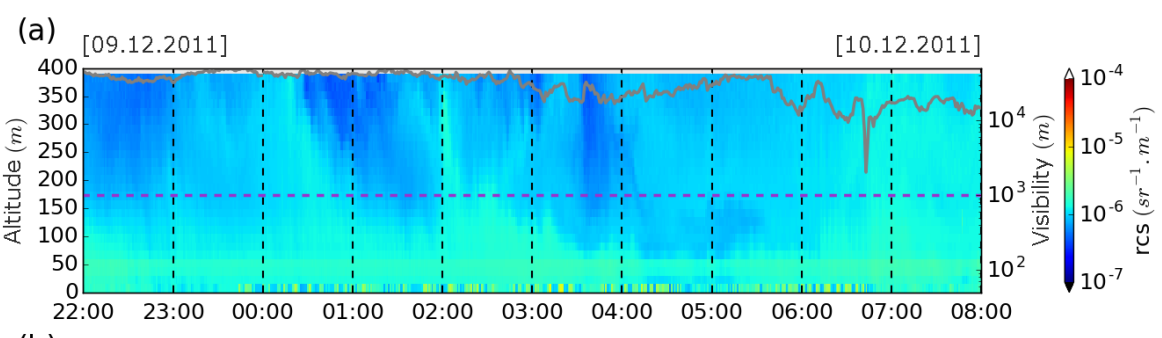

(b)

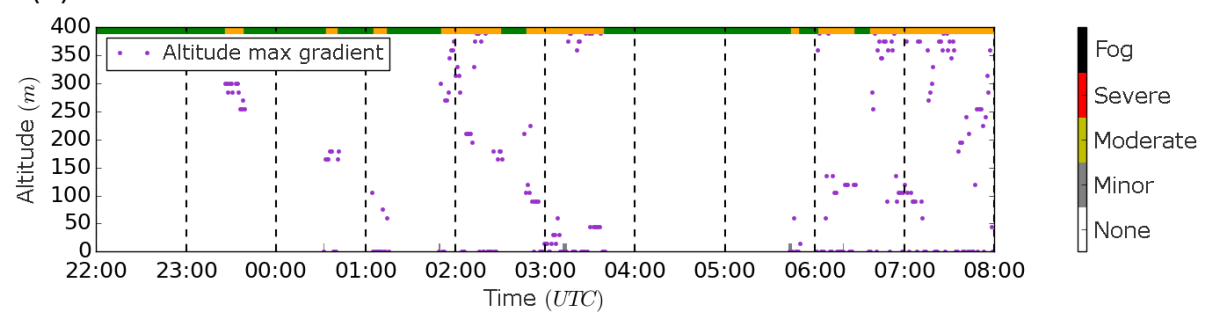

Figure 9. Time series presenting measurements and alert levels in pre-fog conditions on 9-10 December 2011 at SIRTA. (a) ALC-attenuated backscatter (color contours) and horizontal visibility (gray line) measured at $3 \mathrm{~m}$ a.g.l. (b) Alert levels (colors) and altitude of $H_{\text {max }}$. Pre-fog conditions are cloud-free.

\subsection{Reference attenuated backscatter profile}

The hygroscopic growth function, $f_{\beta_{\text {att }}}(\mathrm{RH})$, requires a reference condition, from which the hygroscopic growth will be determined, to be identified. If $\mathrm{RH}<40 \%$, no hygroscopic growth may be considered (i.e., typically called dry conditions). If $\mathrm{RH}<75 \%$, the hygroscopic growth is already initiated, although the size increase is considerably smaller than the increase from $75 \%$ to saturation. The algorithm described in Sect. 4.1 allows us to determine the referenceattenuated backscatter profile $\beta_{\text {att }}\left(r_{j}, \mathrm{RH}_{\mathrm{ref}}\left(t_{\mathrm{ref}}, r_{\mathrm{i}}\right)\right)$ for each pre-fog period. Figure 10 shows the distribution of reference $\beta_{\text {att }}$ profiles between 0 and $400 \mathrm{~m}$ a.g.l. obtained in pre-fog conditions at the time of $\mathrm{RH}_{\text {ref }}$ (median, mean and quartiles) at SIRTA (Fig. 10a and b) and Uccle (Fig. 10c and d). Figure 10a and c show profiles for which the minimum RH near the surface was greater than $75 \%$, while Fig. 10b and d correspond to minimum RH less than $75 \%$. For the driest reference conditions (near-surface $\mathrm{RH}<75 \%$ ), the average attenuated backscatter value $(905 \mathrm{~nm})$ is about $1 \times 10^{-06} \mathrm{sr}^{-1} \mathrm{~m}^{-1}$ at both SIRTA and Uccle. This corresponds to near-surface horizontal visibility greater than $20 \mathrm{~km}$. These profiles appear to be well mixed between 0 and $250 \mathrm{~m}$ a.g.l., with very little attenuation $\left(T^{2}>0.95\right.$, hence the extinction is less than $0.85 \times 10^{-04} \mathrm{~m}^{-1}$ ). The decrease in $\beta_{\text {att }}$ above $300 \mathrm{~m}$ a.g.l. is most likely due to a decrease in aerosol concentration above that layer. Note that at SIRTA a peak attenuated backscatter value is observed at $50 \mathrm{~m}$ a.g.l. This is a known optoelectronic measurement artifact that is discussed in Kotthaus et al. (2016). At Uccle, $\beta_{\text {att }}$ measurements of the CL51 below $50 \mathrm{~m}$ are not used because they could not reliability track the fog formation. For the most moist reference conditions (near- surface $\mathrm{RH}>75 \%$ ), the average surface attenuated backscatter can exceed $2 \times 10^{-06} \mathrm{sr}^{-1} \mathrm{~m}^{-1}$, corresponding to horizontal visibility of about $7-8 \mathrm{~km}$. The average profiles reveal a strong attenuation between the surface and the top of the moist layer near $350 \mathrm{~m}$ a.g.l., with a mean extinction near $2 \times 10^{-03} \mathrm{~m}^{-1}$. This extinction is partially due to scattering by moist aerosols and absorption by water vapor bands at $905 \mathrm{~nm}$ (Wiegner and Gasteiger, 2015).

\subsection{Alert occurrences}

The time at which fog occurrence starts at ground level $(<10$ ma.g.l.) is called fog occurrence time. Prior to this time, various alert levels may occur at altitudes ranging 0 to $400 \mathrm{~m}$ a.g.l. Figure 11 shows, for each altitude above ground level and each time before fog occurrence time, the frequency of occurrence of each alert level including no alert or minor-, moderate-, severe- and fog-level alerts. For each height-time interval, the sum of occurrences of all alert levels $=100 \%$ (incl. no alert). Figure 11a and b represent the alert occurrences based on SIRTA and Uccle data respectively.

We find that moderate-level alerts occur either near the ground ( $<10 \mathrm{~m}$ a.g.1.) or aloft (50-100 m a.g.1.), starting more than $120 \mathrm{~min}$ prior to fog occurrence time. In the period 30 $10 \mathrm{~min}$ prior to fog occurrence time, the frequency of occurrence of moderate-level alerts increases, with higher (in terms of altitude) alerts occurring earlier.

Severe-level alerts occur generally less than $50 \mathrm{~min}$ $(100 \mathrm{~min})$ prior to fog occurrence time at SIRTA (Uccle). SIRTA data show that $15 \mathrm{~min}$ prior to fog occurrence time the severe-level alert occurrence is most frequent at $70 \mathrm{~m}$ a.g.l. The severe-level alert then occurs progressively at lower altitude as the time prior to fog occurrence time decreases. The fog forms at or very close to the surface $(<20 \mathrm{~m}$ a.g.l. $)$ af- 
Table 3. Fog events used to study the occurrence and characteristics of pre-fog alerts (a) at SIRTA and (b) at Uccle.

\begin{tabular}{|c|c|c|c|c|}
\hline $\begin{array}{l}\text { Date } \\
\text { (day/month/year) }\end{array}$ & $\begin{array}{l}\text { Fog occurrence } \\
\text { time (UTC) }\end{array}$ & $\begin{array}{r}\text { Alert } \\
\text { duration } \\
(\min )\end{array}$ & $\begin{array}{r}\mathrm{RH}_{\text {ref }} \\
(\%)\end{array}$ & $\begin{array}{r}\text { Initial } \\
\text { value of } \\
H_{\max }(\mathrm{m})\end{array}$ \\
\hline \multicolumn{5}{|l|}{ (a) SIRTA dev. fog } \\
\hline 13-02-2011 & 04:00 & 20 & 79 & 75 \\
\hline 10-11-2011 & $18: 00$ & 16 & 73 & 90 \\
\hline $15-11-2011$ & 03:00 & 32 & 61 & 135 \\
\hline 16-11-2011 & 01:20 & 24 & 77 & 90 \\
\hline $25-11-2011$ & $21: 40$ & 21 & 98 & 75 \\
\hline 28-11-2011 & $06: 30$ & 23 & 85 & 120 \\
\hline $19-12-2011$ & $05: 10$ & 46 & 63 & 45 \\
\hline 23-10-2012 & 03:40 & 107 & 59 & 300 \\
\hline 24-10-2012 & $03: 40$ & 68 & 73 & 120 \\
\hline 04-11-2012 & $01: 10$ & 23 & 62 & 150 \\
\hline 09-11-2012 & $06: 40$ & 11 & 74 & 45 \\
\hline $14-11-2012$ & 09:30 & 67 & 99 & 195 \\
\hline 20-11-2012 & 03:00 & 4 & 99 & 60 \\
\hline 22-11-2012 & $03: 40$ & 16 & 79 & 60 \\
\hline 30-11-2012 & 19:00 & 4 & 98 & 90 \\
\hline $10-03-2013$ & 05:00 & 24 & 55 & 105 \\
\hline 24-10-2013 & $03: 30$ & 36 & 66 & 120 \\
\hline 10-01-2014 & 03:20 & 10 & 71 & 75 \\
\hline $11-01-2014$ & 09:00 & 3 & 97 & 30 \\
\hline 31-01-2014 & $00: 40$ & 8 & 95 & 60 \\
\hline 22-02-2014 & $23: 10$ & 14 & 71 & 135 \\
\hline 14-03-2014 & $23: 20$ & 47 & 39 & 135 \\
\hline 28-10-2014 & $00: 30$ & 23 & 68 & 60 \\
\hline 27-11-2014 & 00:50 & 2 & 92 & 0 \\
\hline 30-12-2014 & $07: 50$ & 19 & 73 & 30 \\
\hline 03-01-2015 & 01:30 & 7 & 74 & 75 \\
\hline 07-01-2015 & 00:50 & 16 & 71 & 75 \\
\hline $12-02-2015$ & 05:50 & 15 & 62 & 30 \\
\hline $18-02-2015$ & $05: 40$ & 36 & 74 & 75 \\
\hline \multicolumn{5}{|l|}{ (b) Uccle dev. fog } \\
\hline 27-02-2012 & $06: 10$ & 33 & 78 & 120 \\
\hline 04-03-2012 & 02:00 & 76 & 67 & 200 \\
\hline 04-04-2012 & 06:20 & 75 & 39 & 160 \\
\hline 04-05-2012 & 05:30 & 63 & 76 & 110 \\
\hline 20-05-2012 & $22: 20$ & 168 & 57 & 170 \\
\hline 24-10-2012 & $23: 30$ & 91 & 60 & 190 \\
\hline 04-11-2012 & $05: 40$ & 21 & 67 & 140 \\
\hline 18-11-2012 & $19: 30$ & 8 & 87 & 130 \\
\hline $16-01-2013$ & $21: 30$ & 42 & 56 & 160 \\
\hline 23-01-2013 & $00: 10$ & 57 & 92 & 80 \\
\hline $31-05-2013$ & 00:20 & 48 & 79 & 180 \\
\hline 23-09-2013 & 02:00 & 173 & 61 & 200 \\
\hline 27-09-2013 & $02: 50$ & 20 & 53 & 110 \\
\hline 24-10-2013 & 05:00 & 80 & 64 & 110 \\
\hline
\end{tabular}

ter this severe-level alert scenario. A similar result is found based on Uccle data with severe-level alert occurrences exceeding $50 \%$ about $40 \mathrm{~min}$ prior to fog occurrence time at altitudes ranging $50-100 \mathrm{~m}$ a.g.l. Severe-level alerts at
SIRTA also occur at altitudes above fog-level alerts (typically $>70 \mathrm{~m}$ ). These occurrences should likely be fog-level alerts, but at these altitudes the ALC signal does not exceed 

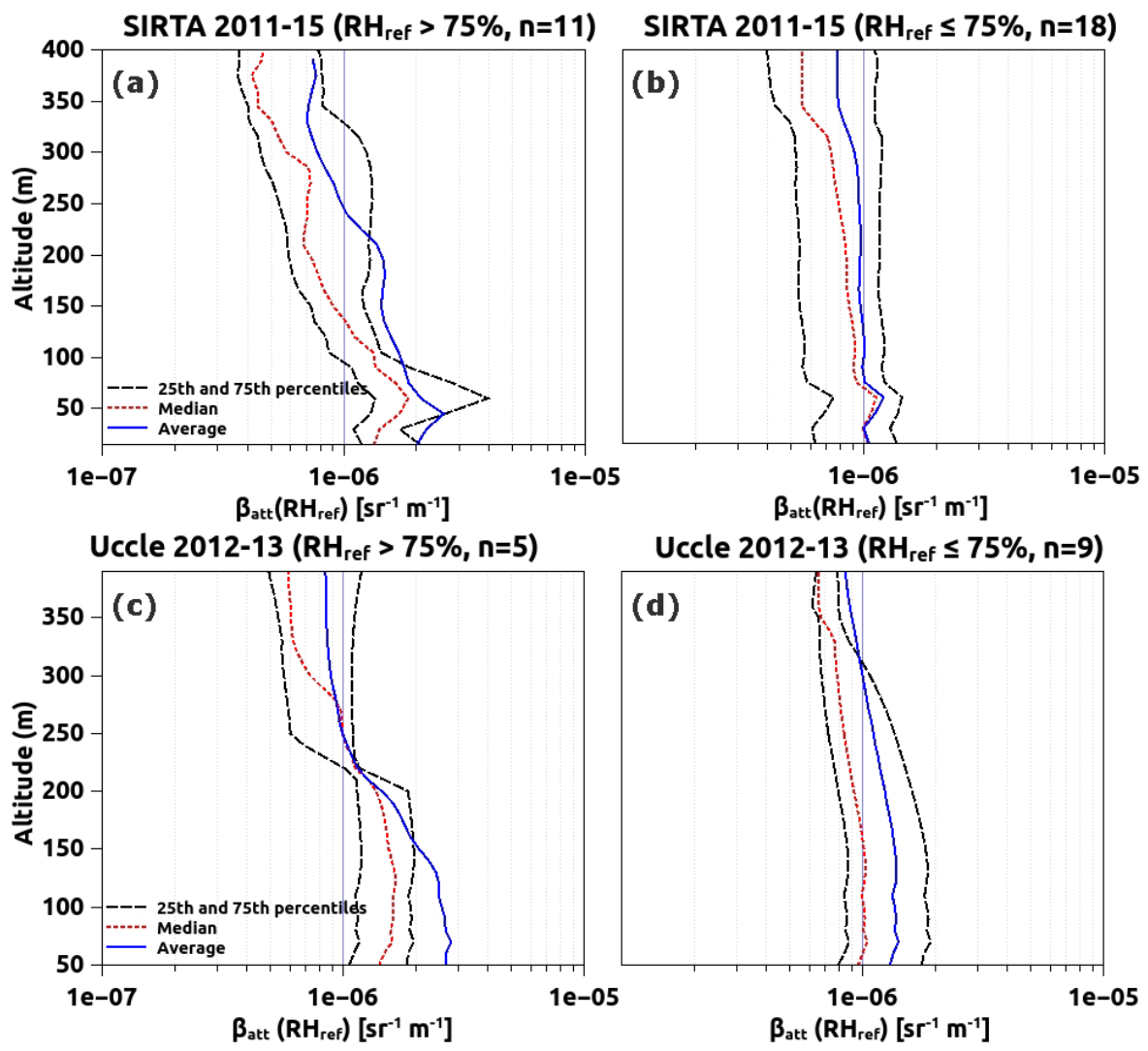

Figure 10. Distribution of reference $\beta_{\text {att }}$ profiles between 0 and $400 \mathrm{~m}$ a.g.l. obtained in pre-fog conditions at the time of $\mathrm{RH}_{\text {ref }}(\mathrm{median}$, mean and quartiles according to the label) at SIRTA $(\mathbf{a}, \mathbf{b})$ and Uccle $(\mathbf{c}, \mathbf{d})$ for which the minimum RH near-surface was greater than $75 \%$ (a, c) and less than $75 \%(\mathbf{b}, \mathbf{d})$.

the fog-level threshold if there is a fog layer below due to strong attenuation.

The fog-level alert is a scenario where the liquid water phase occurs aloft prior to fog occurrence at the ground. This occurrence reveals a time-height relationship showing a progressive increase in the subsidence rate of the fog layer in the few minutes before it reaches the ground.

\subsection{Alert durations}

Alert durations are computed for moderate-, severe- and foglevel alerts. The total alert duration is the time interval between the beginning of a moderate-level alert and the fog occurrence time. During this time interval, moderate-, severeand fog-level alerts are present. The sum of the moderate, severe and fog alert durations corresponds to the total alert duration. The moderate-level alert duration is the time interval during which a moderate-level alert is present. A severe-level alert duration is the time interval during which a severe-level alert is present. A fog-level alert duration is the time interval during which a fog-level alert is present. Note that the foglevel alert stops when the fog occurrence time is reached.
Figure 12 shows that moderate-level-alert durations last 5$20 \mathrm{~min}$ in general at SIRTA and Uccle. They represent about 5 to $30 \%$ of the total alert duration. However, on some occasions at SIRTA, the moderate-level-alert duration can represent more than $50 \%$ of the total alert duration. Severelevel-alert durations last up to $70 \mathrm{~min}$ at Uccle, while they are shorter at SIRTA. They can represent up to $80 \%$ of the total alert duration. Fog-level-alert durations last up to 30 (50) $\mathrm{min}$ at SIRTA (Uccle), representing up to $90 \%$ of total alert durations. This confirms that alerts prior to fog occurrence at the ground can follow different scenarios, some of which include a long fog-level alert aloft prior to fog occurrence at the ground.

Figure 13 shows the effect of RH that was present at the time when the reference $\beta_{\text {att }}$ is chosen. While this $\mathrm{RH}_{\text {ref }}$ is measured near the ground, we concluded from Fig. 10 that it is a good proxy for RH throughout the shallow nighttime mixing layer. For both sites, we find a strong negative correlation between the total alert duration and $\mathrm{RH}_{\text {ref. }}$. This is consistent with the behavior shown in Fig. 4c, illustrating that alerts occur later when reference conditions are more humid. At SIRTA (Uccle) alert durations are reduced by 5 (10) min when $\mathrm{RH}_{\text {ref }}$ increases by $10 \%$. Figure 13 possibly 

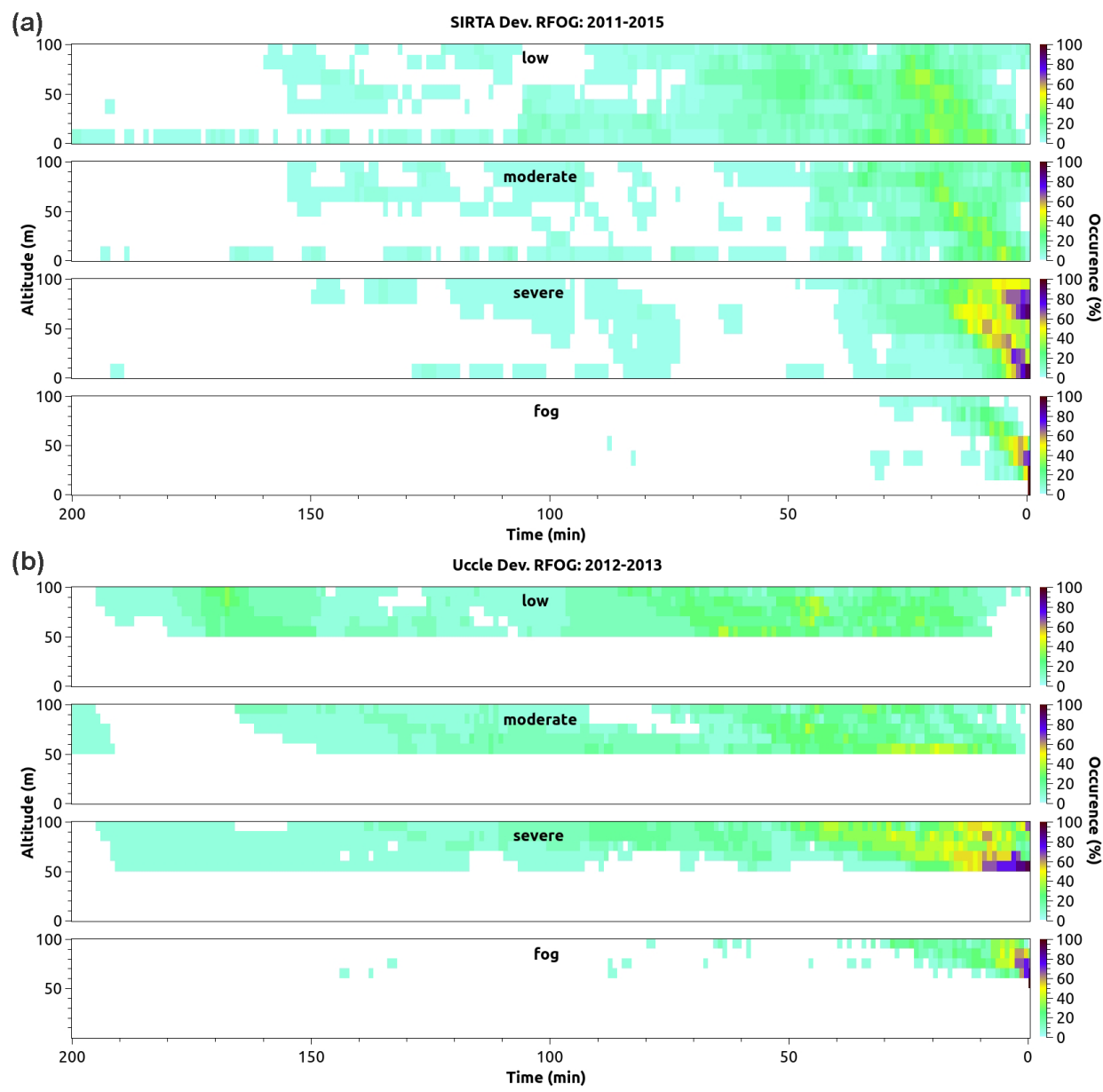

Figure 11. Frequency of occurrence of each alert level (no alert or minor, moderate and severe fog alerts) for each altitude above ground level and each time before fog occurrence time at SIRTA (a) and Uccle (b). For each height-time interval, the sum of occurrence of all alert levels $=100 \%$ (incl. no alert).
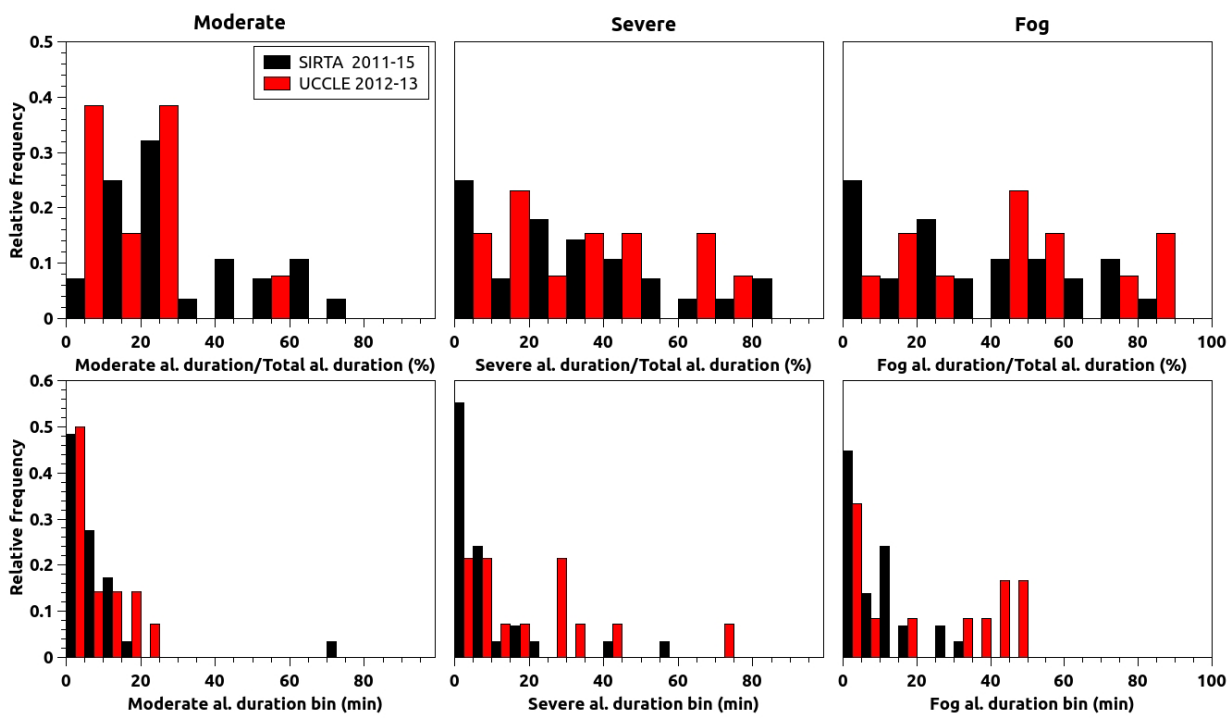

Figure 12. Frequency distribution of alert durations of moderate-, severe- and fog-level alerts at SIRTA (black) and Uccle (red). 


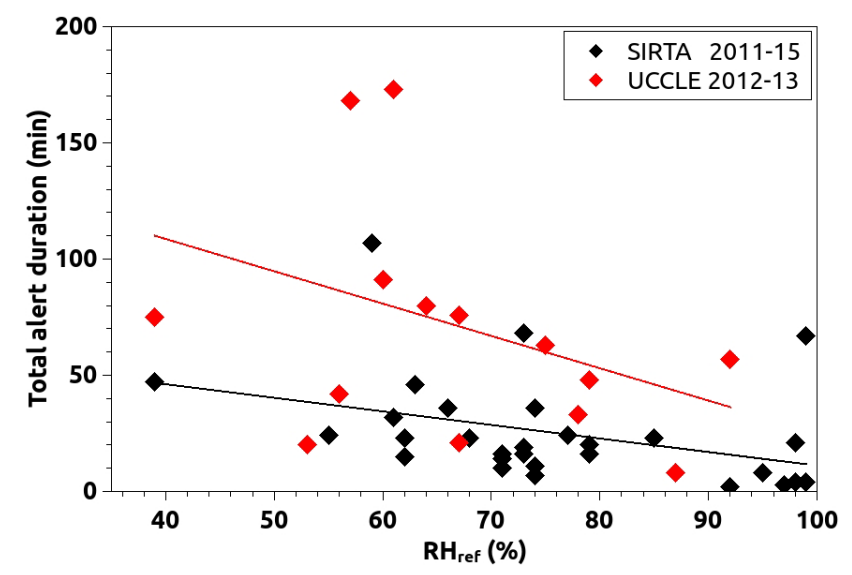

Figure 13. Effect of RH at the time when the reference $\beta_{\text {att }}$ profile is derived on the total alert duration, at SIRTA (back) and Uccle (red).

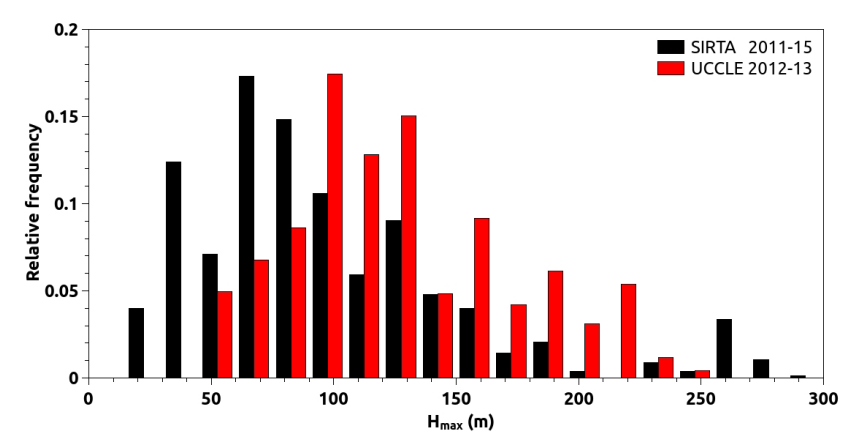

Figure 14. Frequency distribution of the altitude where the maximum ratio gradient occurs at a given time. $H_{\max }$ is determined only when moderate-, severe- or fog-level alerts exist.

reveals two populations. The first population is characterized by shorter alert durations (typically less than $50 \mathrm{~min}$ ) for which alert durations are reduced by $5 \mathrm{~min}$ when $\mathrm{RH}_{\mathrm{ref}}$ increases by $10 \%$. The second population is characterized by longer alert durations (typically greater than $50 \mathrm{~min}$ ) for which alert durations are reduced by $10 \mathrm{~min}$ when $\mathrm{RH}_{\text {ref }}$ increases by $10 \%$. Pre-fog alerts at SIRTA are found predominantly in the first population, while at Uccle alerts are found in both populations.

\subsection{Alert altitudes}

Next we define the altitude, $H_{\max }$, where the maximum ratio gradient occurs at a given time. This parameter traces at which altitude aerosol activation is strongest, identifying the altitude where the highest supersaturation occurs. $H_{\max }$ is determined only when an alert exists. In case of minorlevel alerts, $H_{\max }$ altitudes are found near the surface and aloft, with rapid changes between different altitudes from one time step to the next. In case of moderate-, severe- and foglevel alerts, $H_{\max }$ altitudes behave more consistently with
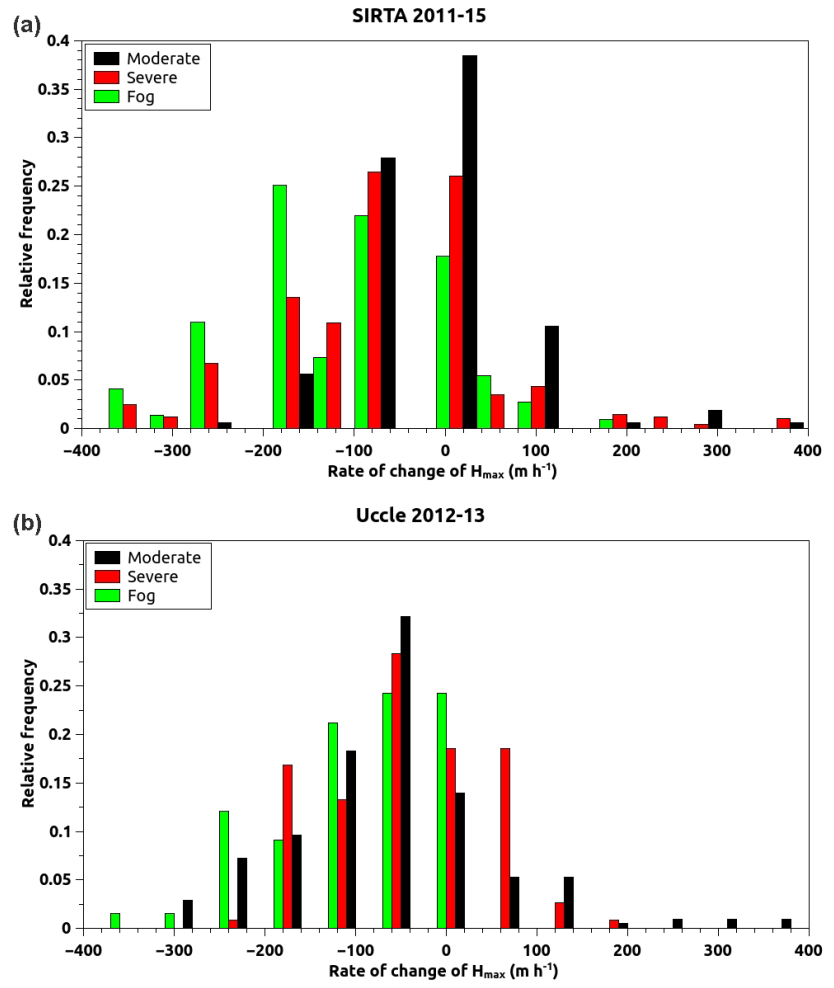

Figure 15. Frequency distribution of rate of change of $H_{\max }$ computed on a $10 \mathrm{~min}$ time interval. When the rate of change is negative (positive), $H_{\max }$ decreases (increases) with time.

time. Hence $H_{\max }$ is only determined for moderate-, severeand fog-level alerts. Figure 14 shows a frequency distribution function of $H_{\max }$ derived from SIRTA and Uccle data. $H_{\max }$ ranges predominantly between 0 and $300 \mathrm{~m}$, with a median (mean) value of 75 (91) $\mathrm{m}$ at SIRTA and 110 (124) $\mathrm{m}$ at Uccle. Lowest possible $H_{\max }$ at Uccle is $50 \mathrm{~m}$ because CL51 data are not exploited below this altitude. Although measurements start at $50 \mathrm{~m}$, a possible explanation for the higher $H_{\max }$ values at Uccle compared to SIRTA is that Uccle is an urban site, located only $5 \mathrm{~km}$ from the city center, while SIRTA is suburban located $20 \mathrm{~km}$ southwest of the city center. The urban site is subject to higher turbulence near the surface due to surface heterogeneities. The 3-D structure of the city canopy generates small-scale turbulence that tends to mix the air in the shallow surface layer. It slows down the cooling of this layer and makes it more difficult to reach supersaturated conditions at the surface. Upward vertical motions can lead to cooling of rising moist plumes, enabling supersaturated conditions to be reached a few tens or hundreds of meters above the ground.

Next we study the rate of change of $H_{\max }$, computed based on $10 \mathrm{~min}$ time intervals. The frequency distribution function of the rate of change of $H_{\max }$ is shown in Fig. 15, for moderate-, severe- and fog-level alerts, based on SIRTA and Uccle data. When the rate of change is negative (posi- 
tive), $H_{\max }$ decreases (increases) with time. Figure 15 shows that the temporal rate of change $\left(\mathrm{m} \mathrm{h}^{-1}\right)$ of $H_{\max }$ ranges predominantly between 0 and $-300 \mathrm{~m} \mathrm{~h}^{-1}$. Positive values are also observed. During moderate-level alerts, the rate of change of $H_{\max }$ is found to range predominantly between +50 and $-50 \mathrm{~m} \mathrm{~h}^{-1}$, with a median (mean) value of 0 $(-25) \mathrm{m} \mathrm{h}^{-1}$ at SIRTA and $-60(-67) \mathrm{m} \mathrm{h}^{-1}$ at Uccle. This reveals that moderate-level alert heights decrease slowly as time approaches the fog occurrence time. During severelevel alerts the median (mean) rate of change of $H_{\max }$ is $-60(-70) \mathrm{m} \mathrm{h}^{-1}$ at SIRTA and $-60(-49) \mathrm{m} \mathrm{h}^{-1}$ at Uccle. Therefore, when a severe-level alert is reached, the height at which this alert occurs, decreases significantly as time approaches the fog occurrence time. When fog-level alerts occur, the median (mean) rate of change of $H_{\max }$ is -125 $(-114) \mathrm{m} \mathrm{h}^{-1}$ at SIRTA and $-60(-102) \mathrm{m} \mathrm{h}^{-1}$ at Uccle, revealing the most rapid rate of decrease of the alert height prior to fog occurrence at the surface.

\section{Conclusions}

We demonstrate that total attenuated backscatter in the nearinfrared can be used as a proxy to track aerosol backscatter coefficient hygroscopic growth. We show that hygroscopic growth functions of aerosol backscatter can be derived using a simple experimental setup including an ALC and a hygrometer on a $30 \mathrm{~m}$ mast. The hygroscopic growth function is defined as the ratio of attenuated backscatter to a reference attenuated backscatter measured in dry conditions. These functions are similar to those found in the literature for other aerosol optical properties. A reliable reference attenuated backscatter profile must be found to track hygroscopic growth of aerosol backscatter. The reference attenuated backscatter profile varies significantly with relative humidity conditions. It has been found that $\mathrm{RH}<75 \%$ produces more reliable reference attenuated backscatter profiles.

In pre-radiation-fog conditions, one usually finds that $\mathrm{RH}$ increases with time, resulting in an increase of attenuated backscatter. Hence the temporal gradient of the attenuated backscatter ratio can be derived. We find that the temporal gradient of attenuated backscatter ratio is less sensitive to initial conditions than the attenuated backscatter ratio itself. Temporal gradients of attenuated backscatter ratio reach threshold values, showing that the aerosol activation process is engaged. In pre-radiation-fog conditions, we find that these thresholds are reached up to $1-3 \mathrm{~h}$ prior to the time of fog occurrence at altitudes ranging from 0 to $250 \mathrm{~m}$ a.g.l.

$H_{\max }$, the altitude of the maximum gradient of attenuated backscatter ratio, is another useful parameter. It reveals at which altitude cooling processes most efficiently lead to aerosol activation. It often reveals that $H_{\max }$ tends to decrease as time reaches the fog occurrence time. We find that $H_{\max }$ is quite variable with time in situations prior to very shallow and patchy radiation fog. Conversely, $H_{\max }$ is rather stable with time prior to deep radiation fog.
Based on measurements carried out at two stations in urban and semi-urban environments, we find that pre-fog alert occurrences and durations depend on the cooling processes leading to supersaturated conditions, and on the reference conditions that can be found. Hence, alert thresholds should be adjusted for each site. Alert durations could be optimized by adapting alert thresholds to relative humidity values found at the reference time. Based on 45 cases studied and given alert thresholds, alert occurrence reaches $100 \%$ $30 \mathrm{~min}(50 \mathrm{~min})$ prior to fog formation at SIRTA (Uccle).

Known limitations in our ability to track hygroscopic growth of aerosols using PARAFOG are (1) the minimum height at which ALC measurements can be reliably used due to ALC optical overlap; (2) water vapor absorption at 905$910 \mathrm{~nm}$ that affects attenuated backscatter values as specific humidity changes; and (3) change in aerosol type (e.g., from marine salt to anthropogenic aerosols) within a few hours prior to fog formation.

The PARAFOG algorithm is currently deployed at the Charles de Gaulle airport in Paris, using CL31 measurements, providing airport forecasters one additional source of information to help them anticipate occurrences of lowvisibility runway conditions.

To further evaluate the performance of PARAFOG, several developments are suggested. (1) A method for objective interpretation of alert levels should be developed to derive hit rates and false alarm rates. (2) Performance tests should be carried out at other locations using datasets that include both pre-fog events and non-fog events. (3) Alert threshold values should be adapted to reference relative humidity, and possibly to aerosol types, using, for example, $\mathrm{PM}_{2.5}$ measurements.

\section{Data availability}

CL31 data, surface meteorological parameters and visibility measurements at SIRTA can be accessed from the SIRTA public data repository that is accessible online at http://www. sirta.fr (SIRTA, 2016). The data policy and a data download are available from the website. CL51 data and surface meteorological parameters are available upon request (laffineur.quentin@meteo.be).

Author contributions. M. Haeffelin and Q. Laffineur designed the experiment and developed the PARAFOG algorithm. J.-A. BravoAranda carried out the simulations presented in Sect. 3. J.A. Casquero-Vera tested the algorithm on a subset of the SIRTA CL31 dataset. M.-A. Drouin coded the PARAFOG algorithm in Python, and adapted it to run automatically on large datasets. J.-C. Dupont provided access to SIRTA data and H. De Baker to Uccle data. M. Haeffelin prepared the manuscript with contributions from all co-authors. 
Acknowledgements. This study was conducted in the framework of the TOPROF (ES1303; http://www.toprof.imaa.cnr.it/) European COST action. The authors would like to acknowledge the EU COST office for its support for scientific meetings and missions. The authors would like to acknowledge Météo-France for providing the CL31 ceilometer deployed at the SIRTA observatory and the Solar-Terrestrial Centre of Excellence (STCE), a research collaboration established by the Belgian federal government through the action plan for reinforcement of the federal scientific institute that funded the CL51 ceilometer deployed in Uccle. The authors would like to acknowledge that the SIRTA observatory, as an H2020 ACTRIS-2 observational facility, receives funding from the European Union's Horizon 2020 Programme for Research and Innovation under grant agreement no. 654109.

Edited by: M. Kulie

Reviewed by: three anonymous referees

\section{References}

Baars, H., Ansmann, A., Engelmann, R., and Althausen, D.: Continuous monitoring of the boundary-layer top with lidar, Atmos. Chem. Phys., 8, 7281-7296, doi:10.5194/acp-8-7281-2008, 2008.

Bergot, T., Escobar, J., and Masson, V.: Effect of small-scale surface heterogeneities and buildings on radiation fog: Large-eddy simulation study at Paris-Charles de Gaulle airport. Q. J. Roy. Meteor. Soc., 141, 285-298, 2015.

Boneh, T., Weymouth, G. T., Newham, P., Potts, R., Bally, J., Nicholson, A. E., and Korb, K. B.: Fog Forecasting for Melbourne Airport Using a Bayesian Decision Network, Weather and Forecast., 30, 1218-1233, 2015.

Dupont, J. C., Haeffelin, M., Stolaki, S., and Elias, T.: Analysis of dynamical and thermal processes driving fog and quasi-fog life cycles using the 2010-2013 ParisFog dataset, Pure Appl. Geophys., 173, 1337-1358, 2016.

Dutta, D. and Chaudhuri, S.: Nowcasting visibility during wintertime fog over the airport of a metropolis of India: decision tree algorithm and artificial neural network approach, Nat. Hazards, 75, 1349-1368, 2015.

Dutta, D. and Chaudhuri, S.: Nowcasting visibility during wintertime fog over the airport of a metropolis of India: decision tree algorithm and artificial neural network approach, Nat. Hazards, 75, 1349-1368, 2015.

Ebert, E. E., Janowiak, J. E., and Kidd, C.: Comparison of nearreal-time precipitation estimates from satellite observations and numerical models. B. Am. Meteorol. Soc., 88, 47-64, 2007.

Elias, T., Haeffelin, M., Drobinski, P., Gomes, L., Rangognio, J., Bergot, T., Chazette, P., Raut, J.-C., and Colomb, M.: Particulate contribution to extinction of visible radiation:pollution, haze, and fog, Atmos. Res., 92, 443-454, 2009.

Glickman, T.: Glossary of Meteorology, 2nd ed., Amer. Meteor. Soc., 855 pp., 2000.

Granados-Muñoz, M. J., Navas-Guzmán, F., Bravo-Aranda, J. A., Guerrero-Rascado, J. L., Lyamani, H., Valenzuela, A., Titos, G., Fernández-Gálvez, J., and Alados-Arboledas, L.: Hygroscopic growth of atmospheric aerosol particles based on active remote sensing and radiosounding measurements: selected cases in southeastern Spain, Atmos. Meas. Tech., 8, 705-718, doi:10.5194/amt-8-705-2015, 2015.

Haeffelin, M., Barthès, L., Bock, O., Boitel, C., Bony, S., Bouniol, D., Chepfer, H., Chiriaco, M., Cuesta, J., Delanoë, J., Drobinski, P., Dufresne, J.-L., Flamant, C., Grall, M., Hodzic, A., Hourdin, F., Lapouge, F., Lemaître, Y., Mathieu, A., Morille, Y., Naud, C., Noël, V., O'Hirok, W., Pelon, J., Pietras, C., Protat, A., Romand, B., Scialom, G., and Vautard, R.: SIRTA, a ground-based atmospheric observatory for cloud and aerosol research, Ann. Geophys., 23, 253-275, doi:10.5194/angeo-23-253-2005, 2005.

Haeffelin, M., Bergot, T., Elias, T., Tardif, R., Carrer, D., Chazette, P., Colomb, M., Drobinski, P., Dupont, E., Dupont, J.-C., Gomes, L., Musson-Genon, L., Pietras, C., Plana-Fattori, A., Protat, A., Rangognio, J., Raut, J.-C., Rémy, S., Richard, D., Sciare, J., and Zhang, X.: PARISFOG: Shedding New Light on Fog Physical Processes, B. Am. Meteorol. Soc., 91, 767-783, 2010.

Haeffelin, M., Angelini, F., Morille, Y., Martucci, G., Frey, S., Gobbi, G.-P., Lolli, S., O’Dowd, C. D., Sauvage, L., XuerefRémy, I., Wastine, B., and Feist, D.: Evaluation of mixing height retrievals from automatic profiling lidars and ceilometers in view of future integrated networks in Europe, Bound.-Lay. Meteorol., 143, 49-75, 2012.

Haeffelin, M., Dupont, J. C., Boyouk, N., Baumgardner, D., Gomes, L., Roberts, G., and Elias, T., A Comparative Study of Radiation Fog and Quasi-Fog Formation Processes during the ParisFog Field Experiment 2007, Pure Appl. Geophys., 170, 2283-2303, 2013.

Hämeri, K., Vakeva, M., Hansson, H.-C., and Laaksonen, A.: Hygroscopic growth of ultrafine ammonium sulfate aerosol measured using an ultrafine tandem differential mobility analyzer, J. Geophys. Res., 105, 22231-22242, 2000.

Hammer, E., Gysel, M., Roberts, G. C., Elias, T., Hofer, J., Hoyle, C. R., Bukowiecki, N., Dupont, J.-C., Burnet, F., Baltensperger, U., and Weingartner, E.: Size-dependent particle activation properties in fog during the ParisFog 2012/13 field campaign, Atmos. Chem. Phys., 14, 10517-10533, doi:10.5194/acp14-10517-2014, 2014.

Hänel, G.: The properties of atmospheric aerosol particles as functions of the relative humidity at thermodynamic equilibrium with the surrounding moist air, Adv. Geophys., 19, 73-188, 1976.

Hatch, C. D., Gierlus, K. M., Schuttlefield, J. D., and Grassian, V. H.: Water adsorption and cloud condensation nuclei activity of calcite and calcite coated with model humic and fulvic acids, Atmos. Environ., 42, 5672-5684, doi:10.1016/j.atmosenv.2008.03.005, 2008.

Kasten, F.: Visibilily forecast in the phase of pre-condensation, Tellus, 21, 631-635, 1969.

Kokkola, H., Romakkaniemi, S., and Laaksonen, A.: On the formation of radiation fogs under heavily polluted conditions, Atmos. Chem. Phys., 3, 581-589, doi:10.5194/acp-3-581-2003, 2003.

Kotchenruther, R. A. and Hobbs, P. V.: Humidification factors of aerosols from biomass burning in Brazil, J. Geophys. Res., 103, 32081-32089, 1998.

Kotchenruther, R. A., Hobbs, P. V., and Hegg, D. A.: Humidification factors for atmospheric aerosols off the mid-Atlantic coast of the United States, J. Geophys. Res., 104, 2239-2251, 1999.

Kotthaus, S., O’Connor, E., Münkel, C., Charlton-Perez, C., Haeffelin, M., Gabey, A. M., and Grimmond, C. S. B.: Recommendations for processing atmospheric attenuated backscatter profiles 
from Vaisala CL31 ceilometers, Atmos. Meas. Tech., 9, 37693791, doi:10.5194/amt-9-3769-2016, 2016.

Madonna, F., Amato, F., Vande Hey, J., and Pappalardo, G.: Ceilometer aerosol profiling versus Raman lidar in the frame of the INTERACT campaign of ACTRIS, Atmos. Meas. Tech., 8, 2207-2223, doi:10.5194/amt-8-2207-2015, 2015.

Markowicz, K. M., Flatau, P. J., Kardas, A. E., Remiszewska, J., Stelmaszczyk, K., and Woeste, L.: Ceilometer retrieval of the boundary layer vertical aerosol extinction structure, J. Atmos. Ocean. Tech., 25, 928-944, 2008.

McMurry, P. H. and Stolzenburg, M. R.: On the sensitivity of particle size to relative humidity for Los Angeles aerosols, Atmos. Environ., 23, 497-507, 1989.

Morille, Y., Haeffelin, M., Drobinski, P., and Pelon, J.: STRAT: An Automated Algorithm to Retrieve the Vertical Structure of the Atmosphere from Single-Channel Lidar Data, J. Atmos. Ocean. Tech., 24, 761-775, 2007.

Nebuloni, R.: Empirical relationships between extinction coefficient and visibility in fog, Appl. Opt. 44, 3795-3804, 2005.

O'Connor, E. J., Illingworth, A. J., and Hogan, R. J.: A technique for autocalibration of cloud lidar, J. Atmos. Ocean. Tech., 21, 777-786, 2004.

Pal, S., Haeffelin, M., and Batchvarova, E.: Exploring a geophysical process-based attribution technique for the determination of the atmospheric boundary layer depth using aerosol lidar and nearsurface meteorological measurements, J. Geophys. Res.-Atmos., 118, 9277-9295, 2013.

Pilinis, C. and Pandis, S. N.: Physical, Chemical and Optical Properties of Aerosols, in: The Handbook of Environmental Chemistry, edited by: Huntzinger, O., Springer Verlag, Heidelberg, Germany, 99-124, 1995.

Pitchford, M. L. and McMurry, P. H.: Relationship between measured water vapor growth and chemistry of atmospheric aerosol for Grand Canyon, Arizona, in winter 1990, Atmos. Environ., 28, 827-839, 1994.

Randriamiarisoa, H., Chazette, P., Couvert, P., Sanak, J., and Mégie, G.: Relative humidity impact on aerosol parameters in a Paris suburban area, Atmos. Chem. Phys., 6, 1389-1407, doi:10.5194/acp-6-1389-2006, 2006.

Raut, J.-C. and Chazette, P.: Retrieval of aerosol complex refractive index from a synergy between lidar, sunphotometer and in situ measurements during LISAIR experiment, Atmos. Chem. Phys., 7, 2797-2815, doi:10.5194/acp-7-2797-2007, 2007.

Rodrigues, P. F., Landulfo, E., Gandu, A. W., da Silva Lopes, F. J., and da Costa, R. F.: Indirect aerosol hygroscopic growth observations with a backscattering lidar, part II: five day breeze onset data analyses, Proc. SPIE 8182, Lidar Technologies, Techniques, and Measurements for Atmospheric Remote Sensing VII, 81820U, doi:10.1117/12.898208, 2011.

Romaán-Cascoón, C., Steeneveld, G. J., Yaguüe, C., Sastre, M., Arrillaga, J. A., and Maqueda, G.: Forecasting radiation fog at climatologically contrasting sites: evaluation of statistical methods and WRF, Q. J. Roy. Meteor. Soc., 2016.

Seinfeld, J. H. and Pandis, S. N.: Atmospheric chemistry and physics: From air pollution to climate change, Wiley, MI, USA, ISBN: 978-0-471-72018-8, 1998.

Semeniuk, T. A., Wise, M. E., Martin, S. T., Russell, L. M., and Buseck, P. R.: Water uptake characteristics of individual atmo- spheric particles having coatings, Atmos. Environ., 41, 62256235, 2007.

SIRTA: CL31 data, surface meteorological parameters and visibility measurements at SIRTA, available at: http://www.sirta.fr, last access: 26 October 2016.

Steeneveld, G. J., Ronda, R. J., and Holtslag, A. A. M.: The challenge of forecasting the onset and development of radiation fog using mesoscale atmospheric models, Bound.-Lay. Meteorol., 154, 265-289, 2015.

Svenningsson, B., Hansson, H.-C., and Wiedensohler, A.: Hygroscopic growth of aerosol particles in the Po Valley, Tellus B, 44, 556-569, 1992.

Titos, G., Jefferson, A., Sheridan, P. J., Andrews, E., Lyamani, H., Alados-Arboledas, L., and Ogren, J. A.: Aerosol light-scattering enhancement due to water uptake during the TCAP campaign, Atmos. Chem. Phys., 14, 7031-7043, doi:10.5194/acp-14-70312014, 2014a.

Titos, G., Lyamani, H., Cazorla, A., Sorribas, M., Foyo-Moreno, I., Widensohler A., and Alados-Arboledas, A.: Study of the relative humidity dependence of aerosol light-scattering in southern Spain, Tellus B, 66, 24536, doi:10.3402/tellusb.v66.24536, 2014b.

Van Schalkwyk, L. and Dyson, L. L.: Climatological characteristics of fog at Cape Town International airport, Weather Forecast., 28, 631-646, 2013.

Veljović, K., Vujović, D., Lazić, L., and Vučković, V.: An analysis of fog events at Belgrade International Airport, Theor. Appl. Climatol., 119, 13-24, 2015.

Veselovskii, I., Whiteman, D. N., Kolgotin, A., Andrews, E., and Korenskii, M.: Demonstration of aerosol property profiling by multiwavelength lidar under varying relative humidity conditions, J. Atmos. Ocean. Tech., 26, 1543-1557, 2009.

Wiegner, M. and Gasteiger, J.: Correction of water vapor absorption for aerosol remote sensing with ceilometers, Atmos. Meas. Tech., 8, 3971-3984, doi:10.5194/amt-8-3971-2015, 2015.

Wiegner, M. and Geiß, A.: Aerosol profiling with the Jenoptik ceilometer CHM15kx, Atmos. Meas. Tech., 5, 1953-1964, doi:10.5194/amt-5-1953-2012, 2012.

Wiegner, M., Madonna, F., Binietoglou, I., Forkel, R., Gasteiger, J., Geiß, A., Pappalardo, G., Schäfer, K., and Thomas, W.: What is the benefit of ceilometers for aerosol remote sensing? An answer from EARLINET, Atmos. Meas. Tech., 7, 1979-1997, doi:10.5194/amt-7-1979-2014, 2014.

Winkler, P.: The growth of atmospheric aerosol particles as a function of the relative humidity-II. An improved concept of mixed nuclei, Aerosol Science, 4, 373-387, 1973.

Wulfmeyer, V. and Feingold, G.: On the relationship between relative humidity and particle backscattering coefficient in the marine boundary layer determined with differential absorption lidar, J. Geophys. Res., 105, 4729-4741, 2000.

Zhang, R., Khalizov, A. F., Pagels, J., Zhang, D., Xue, H., and McMurry, P. H.: Variability in morphology, hygroscopicity and optical properties of soot aerosols during atmospheric processing, P. Natl. Acad. Sci. USA, 105, 10291-10296, doi:10.1073/pnas.0804860105, 2008.

Zieger, P., Fierz-Schmidhauser, R., Weingartner, E., and Baltensperger, U.: Effects of relative humidity on aerosol light scattering: results from different European sites, Atmos. Chem. Phys., 13, 10609-10631, doi:10.5194/acp-13-10609-2013, 2013. 